\title{
Final Report, FY 2001200 East Vadose Test Site Hanford Washington Electrical Resistance Tomography
}

\author{
A. Ramirez, W. Daily, A. Binley
}

June 30, 2001

U.S. Department of Energy

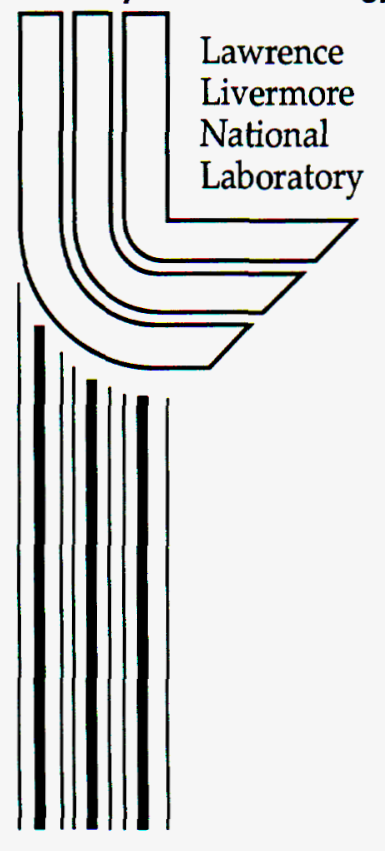




\section{DISCLAIMER}

This document was prepared as an account of work sponsored by an agency of the United States Government. Neither the United States Government nor the University of California nor any of their employees, makes any warranty, express or implied, or assumes any legal liability or responsibility for the accuracy, completeness, or usefulness of any information, apparatus, product, or process disclosed, or represents that its use would not infringe privately owned rights. Reference herein to any specific commercial product, process, or service by trade name, trademark, manufacturer, or otherwise, does not necessarily constitute or imply its endorsement, recommendation, or favoring by the United States Government or the University of California. The views and opinions of authors expressed herein do not necessarily state or reflect those of the United States Government or the University of California, and shall not be used for advertising or product endorsement purposes.

This work was performed under the auspices of the U. S. Department of Energy by the University of California, Lawrence Livermore National Laboratory under Contract No. W-7405-Eng-48.

This report has been reproduced directly from the best available copy.

Available electronically at http://www.doe.gov/bridge

Available for a processing fee to U.S. Department of Energy

and its contractors in paper from

U.S. Department of Energy

Office of Scientific and Technical Information

P.O. Box 62

Oak Ridge, TN 37831-0062

Telephone: (865) 576-8401

Facsimile: (865) 576-5728

E-mail: reports@adonis.osti.gov

Available for the sale to the public from

U.S. Department of Commerce

National Technical Information Service

5285 Port Royal Road

Springfield, VA 22161

Telephone: (800) 553-6847

Facsimile: (703) 605-6900

E-mail: orders@ntis.fedworld.gov

Online ordering: http://www.ntis.gov/ordering.htm

OR

Lawrence Livermore National Laboratory

Technical Information Department's Digital Library

http://www.llnl.gov/tid/Library.html 


\title{
FINAL REPORT, FY 2001
}

\section{EAST VADOSE TEST SITE HANFORD WASHINGTON}

\section{Electrical Resistance Tomography}

\author{
Submitted \\ June 30, 2001 \\ By
}
Abelardo Ramirez ${ }^{1}$, William Daily ${ }^{1}$, and Andrew Binley ${ }^{2}$
${ }^{1}$ Lawrence Livermore National Laboratory
Livermore, CA 94550
${ }^{2}$ Lancaster University
Lancaster, England

\section{INTRODUCTION}

This report covers the electrical resistance tomography (ERT) work performed at the Hanford Reservation, 200 East Area Vadose test (Sisson and Lu) site during the period March 23 through May 5, 2001.

The purposes of the ERT work were to:

1- Compare and contrast the development of the highly concentrated sodium thiosulfate plume (FY 01 work) with the fresh river water plume observed during FY 00. 2- Use the resistance images to infer the dynamics of the plume during two or three of the sodium thio-sulfate releases and during the water "chaser" release.

3- Determine the influence of the site's steel casings on the ability to construct reliable ERT images.

4- Determine if the steel casings at the site can be used as long electrodes to provide useful images of at least one release.

5- Develop quantitative estimates of the noise in the data and its effect on reconstructed images. 
Eleven electrode arrays (nine electrodes arrays available for the FY00 work), each with 15 electrodes, were installed at the site. These were used to perform 3D surveys before, during, and after 3 different spills.

\section{Site Layout}

Perspective views of the electrode arrays at the test site are shown in Figure 1. Eight ERT arrays are arranged around the periphery of the site with three additional arrays near the center of the pattern. Applied Research Associates installed these arrays using a cone penetrometer method. Each array consists of 15 stainless steel electrodes spaced 1 meter apart (from center to center) between the depths of 19 and $5 \mathrm{~m}$ (see figure 1). These arrays were used to collect 3D surveys of the test site using ERT.

We used three of the arrays located on the SE quadrant of the site to collect fast 3D surveys that recorded a detailed time history of some of the spills; the top third of Figure 1 depicts this arrangement. The three arrays sampled a pie-shaped region extending between 5 and $14 \mathrm{~m}$. depths; only the top 10 electrodes in each array were used to allow for fast data collection times. These arrays were selected because previous experience at the site indicated that migrating plumes tended to move from the injection point towards the SE. We will refer to the tomographs calculated with this data as the pie-shaped tomographs.

We also collected detailed 3D surveys of the whole test site by using all 11 electrode arrays (165 electrodes). The region sampled in this manner extended from 5 to $19 \mathrm{~m}$ depth. The middle part of Figure 1 illustrates this arrangement. We believe that these surveys offer the highest level of sensitivity and spatial resolution of all the data collected We will refer to the tomographs calculated with this data as the whole-site tomographs.

In addition to the "point electrode" arrays discussed above, 30 steel casings installed for a previous test at the site were used as "long electrodes" as depicted by the bottom part of Figure 1. The purpose of these measurements was to determine the feasibility of using steel casings present in tank farms for ERT imaging. Using data from these electrodes, we expected to get 2D images of horizontal plume structure only (no sensitivity to vertical structure). The region sampled by these long electrodes extends from 0 to $19 \mathrm{~m}$. We elected to only image the region where the plume was most likely to penetrate, i.e., the region between 5 and $19 \mathrm{~m}$. We will refer to the tomographs calculated with these data as the long electrode tomographs. In addition, we considered the possibility of combining long electrode data with point electrode data; tomographs calculated with the combined data set offer horizontal and vertical resolution of the plume.

Data acquisition trips to the site were planned to yield maximum coverage of the overall test with minimum travel costs. As indicated in Figure 2, site visits occurred on 3/24$26 / 01$ (baseline measurements), during the $1^{\text {st }}$ spill on $3 / 30 / 01$, during the $3^{\text {rd }}$ spill on $4 / 10$ - 
$11 / 01$, and during the fresh water chaser spill ending on 5/4/01. With this strategy, we collected before, during and after data for releases 1 and 3 (sodium thio-sulfate solution released), and before, during and after spill 6 (fresh water chaser).

\section{What is ERT?}

Electrical resistance tomography (ERT) is a technique for imaging the subsurface electrical structure using conduction currents. From a series of electrodes, low frequency electrical current is injected into the subsurface and the resulting potential distribution measured. A large variety of different source and receiver orientations are used to sample the target volume from many different views. From that data, a computer model of the electrical resistivity distribution is found that produces, to within some predetermined tolerance, the measured potential field. ERT was proposed twenty-two years ago independently by Henderson and Webster (1978) as a medical imaging modality and by Lytle and Dines (1978) as a geophysical imaging tool.

Early development in geophysics was confined to imaging rock core samples in the laboratory (Daily et al., 1987), but prototype data collection hardware and research grade inverse codes suitable for field scale applications soon followed (Ramirez et al., 1993). More recently, ERT has been developed to detect leaks from large storage tanks (Ramirez et al., 1996), monitor underground air sparging (LaBrecque et al., 1996b) and map movement of contaminant plumes (Daily et al., 1998). During this entire period, data acquisition hardware and inversion algorithms have been rapidly improving to handle the new challenges.

The ERT algorithm we used is based on an Occam's type inversion that yields a minimum roughness solution consistent with the data and their errors. The 2 dimensional algorithm, based on a finite element forward solver, is described by LaBrecque et al. (1996a). Also discussed are mesh requirements used for both the $2 \mathrm{D}$ and $3 \mathrm{D}$ algorithms. A simple generalization of this approach to 3 dimensions is not practical, being computationally inefficient. However, LaBrecque et al. (1999) describe a method for streamlining the forward solver using an iterative finite difference formulation and a method to reduce the computational load associated with the Occam's approach. These changes make 3D inversion practical. Convergence for both algorithms is achieved when the root mean square error, normalized by the weights, is equal to the number of data.

\section{Finite Difference Mesh Used}

The finite difference mesh consisted of 40 elements along the $\mathrm{X}$ and $\mathrm{Y}$ axes, and 43 elements along the $\mathrm{Z}$ axis. Within the region of interest (the region completely surrounded by boreholes), there were 20 elements along X, 20 elements along $\mathrm{Y}$ and 34 elements along $Z$. A total of 165 electrodes were included in the problem. The size of the voxels in the region of interest was $0.67 \mathrm{~m}$ along $X, 0.67 \mathrm{~m}$ along $Y$ and $0.5 \mathrm{~m}$ along $Z$. In addition, the 33 steel casings present at the test site were modeled as regions of low electrical 
resistivity with a contrast of $10^{-4}: 1$ relative to the initial model of the surrounding soil. The contrast between the steel casing and the soil was determined based on two point resistance measurements made using the casings, and on knowledge of the soil's electrical conductivity (using resistivity logs collected by ARA when the electrodes arrays were installed. A numerical model was used to adjust the contrast between the steel casings and soil until the calculated values approximately matched the two point resistance measurements made in the field.

\section{Numerical Modeling:}

Estimates of changes in soil resistivity caused by plume infiltration

Infiltration of the sodium thio-sulfate solution caused increases in pore fluid salinity and increases in saturation. We have used Archie's equation to estimate soil resistivity as a function of saturation and the pore fluid's resistivity. The results of this simple model are shown in Figure 3. We calibrated the model to produce a bulk resistivity of $1000 \mathrm{ohm}-\mathrm{m}$ based on the resistivity logs measured by Applied Research Assoc. prior to the start of the FY 00 work. The model assumed that the ambient properties were as follows: saturation was 0.3 , porosity was 0.3 and the resistivity of the ambient pore fluid was 30 ohm-m (a factor of 2.5 smaller than river water). Measurements of the resistivities for the various fluids considered are shown in Figure 3.

The curves in Figure 3 help illustrate that the primary mechanism affecting the measured changes in resistivity is the change in fluid salinity created by the highly conducting, sodium thio-sulfate brine. If we assume that the brine causes the fluid conductivity to change from $30 \mathrm{ohm}-\mathrm{m}$ to $0.3 \mathrm{ohm}$, the bulk resistivity changes a factor of 100 . Conversely, if the salinity remains fixed while the saturation changes from 0.3 to 1.0 , the bulk resistivity changes a factor of about 5 . This suggests that, for the case of sodium thio-sulfate infiltration, the tomographs of resistivity change are 20 times more sensitive to salinity changes than to saturation changes.

\section{Effects of steel casings}

One of the unique aspects of the test site is the presence of closely spaced, multiple steel casings. The electrical properties of steel (approx. $10^{-8} \mathrm{ohm}-\mathrm{m}$ for fresh steel) are dramatically different from those of the soil at the test site (approx. $10^{3} \mathrm{ohm}-\mathrm{m}$ ). This means that the steel casings form paths of least resistance where the electricity flows preferentially. We have performed a limited numerical modeling study to better understand and quantify the shunting effect created by the presence of the casings.

The modeling study included two cases: the pie-shaped region, and the whole test site. We varied the electrical resistivity contrast between the anomaly and the surrounding soil, and considered cases were the steel casings were both absent and present. 
Figure 4 illustrates the results obtained for the pie-shaped region. The upper left side of the figure shows the shape of the anomaly, location, and volume of the change anomaly. The solid white lines indicate the location of the electrode arrays used to sample the region. The dashed lines indicate the location of steel casings located within the region of interest. The column of images below the label "Change $=9 \mathrm{X}$ " show the results obtained when the resistivity contrast between the background soil and the anomaly is 9:1. The results are shown as ratios of resistivity, where the resistivity for the case containing the anomaly is divided by the baseline resistivity. Within the column, the three different images show the same result displayed using three different transparencies so that we can look at the anomaly within the volume with varying levels of sensitivity. The transparencies indicated in the Figure are indicated in units of $\log 10$ resistivity ratio. For example, when the transparency level is indicated between -0.1 to 0.1 , this means that all resistivity ratio values within the range of $10^{-0.1}$ to $10^{0.1}$ are transparent and values outside of this range are opaque. The images in the column below the label "Change $=200 \mathrm{X}$ ", show the results obtained when the resistivity contrast between the background soil and the anomaly is 200:1; we believe that this result most closely represents the conditions present at the Sisson and Lu site. The rightmost column of images in the figure shows the results obtained when there are no steel casings in the problem, and the contrast between the soil and the anomaly is 200:1.

A comparison of the images in Figure 4 leads us to the following observations. The shunting effect of the casings is observable in the pie-shaped tomograph, but it is relatively minor. Note that there are minor differences between the images calculated with and without the casings at a contrast of 200:1. The images calculated with the casings in the problem show a somewhat longer vertical extent than those calculated without the casings. A comparison of the images corresponding to the 9:1 and 200:1 contrasts (casings included in both cases), suggest that effect of a higher contrast is just as important as the effects of the casings on the longer vertical extent of the anomaly.

The results suggest that for the case of 200:1 contrast, any resistivity ratio that falls in the range of $10^{-0.05}$ to $10^{0.05}$ (ratios of 0.9 and 1.1 respectively) and located in the area below the $12 \mathrm{~m}$ layer, is likely caused by vertical smearing of the anomaly. For ratios outside this range, vertical smearing of the anomaly is unlikely to explain the values observed. Thus, when we interpret the field results, we should only consider values smaller than $10^{-0.05}$ (ratios smaller than 0.9 ) as reliable indicators of plume penetration below the $12 \mathrm{~m}$ layer. We recognize that there is some uncertainty regarding were to set the dividing line between reliable and unreliable values.

We now discuss the modeling results for the whole site tomograph. Figure 5 illustrates the results obtained for this case. The upper left side of the figure shows the shape, location, and volume of the change anomaly. Note that the anomaly exists between 5 and $11 \mathrm{~m}$ depth, and that its is slightly off the center of the volume of interest. The dark ellipses shown at the top indicate the locations of the eleven electrode arrays projected at $5 \mathrm{~m}$ 
depth. The white ellipses located at the bottom of the image region are the projections of the steel casings at the $19 \mathrm{~m}$ level. In Figure 5, the column of images below the label "Change $=9 \mathrm{X}$ " show the results obtained when the resistivity contrast between the background soil and the anomaly is $9: 1$. Within the column, the different images show the same result displayed using three different transparencies levels so that we can look at the anomaly within the volume with varying levels of sensitivity. The rest of the figure is structured in the same manner as Figure 4.

The images in Figure 5 leads us to the following observations. The shunting effect of the casings is more significant than the results corresponding to the pie shaped region (Fig. 4). The images calculated with the casings in the problem show substantially longer vertical extent than those calculated without the casings. Note that the anomalies display an inverted bullet shape where the tip of the bullet roughly coincides with the center of the steel casing layout; this occurs even though the anomaly is slightly off-centered. The highest density of casings per unit area is in the center of the volume under study. We believe that this is the reason why the maximum amount of vertical smearing (i.e., the point of the bullet) is observed in this area. A comparison of the images corresponding to the 9:1 and 200:1 contrasts (casings included in both cases), indicates that the higher contrast also contributes to the exaggerated vertical extent of the anomaly. The combination of high anomaly contrast and steel casings causes significant vertical smearing which needs to be accounted for when interpreting the images.

The results suggest that for the case of 200:1 contrast, any resistivity ratio that falls in the range of $10^{-0.3}$ to $10^{0.3}$ (ratios of 0.5 and 2.0 respectively) and is located in the area below the $12 \mathrm{~m}$ layer, is likely to be caused by vertical smearing of the anomaly. For ratios outside this range, vertical smearing of the anomaly is unlikely to explain the values observed. This means that when we interpret the field results, we should only consider values smaller than $10^{-0.3}$ (ratios smaller than 0.5 ) as reliable indicators of plume penetration below the $12 \mathrm{~m}$ layer.

What is the solution to this shorting effect from the casings? Short of removing the steel casings from the site, we believe there is no perfect solution. A partial solution is to correctly model these casings in the data analysis. This approach allows the numerical model to account for casing effects, thereby minimizing the presence of phantoms in the image.

\section{ERT Field Results and Discussion:}

Error analysis, whole site tomographs

A defensible interpretation of ERT requires an estimate of the effect of measurement error on the reconstructed images. Although it is not possible to measure the data errors, we have found that reciprocity yields the best estimate of data error. [The reciprocal of a 
measurement is made by interchanging the source and receiver dipole locations.] If reciprocal pairs of measurements (we will call one 'normal' and the other 'reciprocal') are identical, we will assume that they are error free. Of course, the pairs are never identical and we assume the difference is a measure of the error. Because we need the effects of these errors on the images, our procedure is to use the normal data to calculate an image and then the reciprocal data taken at the same times to calculate an image. The difference between these tomographs produces an estimate of the effects of error on them and can yield a defendable interpretation. Anomalies that are present on both images and show similar location, size, shape and magnitude are much more likely to be real than anomalies show up on one image and not in the other.

Figure 6 compares images for spill 1 where the reconstruction is accomplished using only the normal measurement of transfer resistance measured before and after the spill (image on the left). The image on the right of the figure is the image using only the corresponding reciprocal data. To show the differences, the tomographs are displayed using various transparency levels: values between $10^{-0.15}$ to $10^{0.15}$ (ratios of 0.71 and 1.41 respectively), $10^{-0.2}$ to $10^{0.2}$ (ratios of 0.63 and 1.59 respectively), and $10^{-0.25}$ to $10^{0.25}$ (ratios of 0.56 and 1.78 respectively), made transparent. We see that errors propagate through the analysis to create some differences in the two images. The images are similar for the range of $10^{-0.25}$ to $10^{0.25}$. Our experience suggests that this level of error is unusually high; typically the errors are around 5\%. The reason for this unusually high level of error is unclear. Perhaps it is due to the presence of numerous metallic casings at the site, and the high change in resistivity created by the sodium thio-sulfate solution. We also note that this level of error is small relative to the large change $\left(10^{2}\right)$ created by the sodium thio-sulfate solution. This level of error is somewhat smaller than the $10^{-0.3}$ threshold set to account for smearing effects due to the steel casings. Thus, we choose to use the $10^{-0.3}$ threshold because it is the most conservative of the two values.

This approach can be used to minimize the possibility of false positive predictions, i.e, a prediction that there is a plume present when there is no plume. By comparing anomalies in the normal and reciprocal images, one can evaluate the reliability of the anomalies by examining the similarities (or lack thereof) of the anomalies. Any anomaly that is present in one image but not in the other can be regarded as unreliable. Images that show similar location and shapes in both images are very likely to be real because it is very unlikely that the normal and reciprocal data would be contaminated with exactly the same level of measurement error.

\section{Data Processing Approach:}

The most accurate analysis we can do with the ERT data is a full three-dimensional inversion. This requires a large amount of highly accurate data (reciprocal to at least 1\%). We combined data taken from several subsets of the 165 available electrodes (15 electrodes in 11 different arrays). Nine subsets were taken, each survey subset using 30 electrodes located in 4 separate arrays. A different grouping of electrodes located in the 
same 4 arrays would then be used, and the process was repeated once more until all electrodes in the four arrays were used. Then, the system was connected to 4 new electrode arrays and the process was repeated until all available electrode arrays had been used. Taken together these surveys yielded 7290 measurements for each 3D survey and this took about 4 hours to acquire.

The first 3D data set was taken March $25^{\text {th }}$ as a baseline for the experiment. Additional data sets were collected on $3 / 31 / 01,4 / 10 / 10,5 / 1 / 01$ and 5/4/01. We chose to use a differential technique that calculates resistivity change instead of absolute resistivity. This approach reduces the distortions caused by the steel casings on the observed changes.

We successfully reconstructed values of transfer resistance $R_{D}$ measured during the release, after modifying each value as follows:

$$
\mathrm{R}_{\mathrm{D}}\left(\mathrm{R}_{\mathrm{H}} / \mathrm{R}_{\mathrm{B}}\right)
$$

Where $\left(R_{H} / R_{B}\right)$ is a ratio of corresponding transfer resistance values from a homogeneously resistive half space model and the baseline value. The reason for this procedure is the empirical discovery that it removes from the reconstructed image some of the effects of site conditions that cannot be exactly modeled by the forward solver in the code (i.e., the high conductivity effects of the steel cased boreholes).

\section{Dimensional images of resistivity changes, whole test site}

We have been able to use the approach described by equation (1) to successfully calculate images of resistivity change. Under these conditions the algorithm is much less sensitive to the initial roughness paramete inaccurate representations of the casings. The result of this ratio technique is an image of fractional comparison for each voxel value $f=\rho_{\mathrm{t}} / \rho_{\text {base }}$; $\rho_{\mathrm{t}}$ is the resistivity at some time $t$ and $\rho_{\text {base }}$ is the resistivity corresponding to $3 / 25 / 01$ before the start of the releases. For example, if $f=1$ the resistivity $\rho_{\mathrm{t}}$ has not changed from the baseline value $\rho_{\text {base }}$. When $f=0.8$ the resistivity has decreased to $80 \%$ of the baseline value.

We will first make comparisons between the neutron data and the tomographs of resistivity change. Figure 7 compares an ERT tomograph with neutron survey profiles obtained along three boreholes (H2, H4, and $\mathrm{H} 6)$. The neutron data were collected by researchers at Pacific Northwest National Laboratory led by Dr. Glendon Gee. The left side of the figure shows a diagonal slice through the tomograph block; the slice approximately coincides with the plane defined by the three neutron monitoring boreholes shown. The black dots on top of the tomograph indicate the location of the electrode arrays, and the white ellipses indicate the location of all neutron boreholes. The dotted lines show the approximate location of fine-grained units that in past experiments have 
affected movement of fluids through the vadose zone. On the right side of the figure, are three profiles showing the difference (relative to baseline values obtained before the first spill occurred) in the neutron data for the three holes selected.

When interpreting these comparisons, it is important to remember that the dominant mechanism that causes changes in the neutron data is saturation change. For this experiment, the dominant mechanism that causes resistivity change is the changing salinity of the pore fluid. In areas were saturation changes a small amount, it may be hard to detect the change with the neutron surveys. However, even a small change in saturation caused by the highly concentrated brine can cause very large changes in pore fluid salinity which result in very large resistivity decreases. According to Figure 3, large changes in resistivity are possible even when little or no saturation change occurs because the sodium thio-sulfate causes large changes in pore fluid salinity. This suggests that the tomographs may be more sensitive to small amounts of localized brine infiltration than the neutron data.

The tomograph shows a region of strong resistivity decreases (small resistivity ratios indicated by the blue and purple colors) that extend from 5 to $19 \mathrm{~m}$ depth. Above the 12 $\mathrm{m}$ layer, the region of strong changes is wider than below the layer. Below the layer, the region of strong changes suggests a vertically oriented "finger".

We have chosen the neutron logs for $5 / 4$ and $5 / 11 / 01$ because they show significantly different behavior below the $12 \mathrm{~m}$, fine-grained layer. The logs show large moisture content increases above the $12 \mathrm{~m}$ layer on 5/4/01, and smaller increases on 5/11/01. Below the $12 \mathrm{~m}$ layer, the neutron profiles of 5/11/01 suggest large saturation increases that are not present in the 5/4/01 data. Note that the 5/11/01 moisture content increase below the $12 \mathrm{~m}$ layer corroborates the existence of the finger-like anomaly observed in the tomographs below $12 \mathrm{~m}$. This comparison suggests that the resistivity changes (measured on $5 / 4 / 01$ ) detect the penetration of the $12 \mathrm{~m}$ layer before the neutron logs.

We believe that ERT is more sensitive to a narrow brine finger because the tomographs are primarily sensitive to pore-fluid salinity changes and the neutron logs are sensitive to saturation changes. According to Figure 3, it is possible that small fingers of brine can locally change the fluid conductivity a large amount while the saturation changes relatively little. This hypothesis implies that the tomographs would have a higher sensitivity to these localized changes than the neutron surveys. As more time passes additional moisture moves into these localized areas thereby increasing the moisture content above the threshold were the neutron surveys detect it.

We now wish to compare volume renderings of an ERT tomograph and of neutron data. This comparison is shown in Figure 8. The left column of images in Figure 8 shows a resistivity tomograph $(5 / 4 / 01)$ using two different transparencies. The top image shows all resistivity ratio values between $1.0\left(10^{0.0}\right)$ and $0.5\left(10^{-0.3}\right)$ as transparent. The bottom 
image shows all resistivity ratio values between $1.0\left(10^{0.0}\right)$ and $0.18\left(10^{-0.75}\right)$ as transparent. The right column of images shows a volume rendering of linearly interpolated, neutron differences for $5 / 11 / 01$. The neutron image is also displayed using two transparency levels. The top image shows as transparent all voxels having neutron differences between -0.01 and 0.01 (fractional volume percent). The bottom image shows as transparent all voxels having neutron differences between -0.02 and 0.02 .

There are similarities and differences between the ERT and neutron images. In general, both images suggest a wider extent of the plume above the $12 \mathrm{~m}$ layer than below it. Both images suggest that the plume has moved primarily downward from the release point. There is little indication of lateral spreading to the North and West of the release point, and the bulk of the plume is located on the SE quadrant of the site. The neutron and ERT images indicate that penetration of the $12 \mathrm{~m}$ fine grained layer has occurred in roughly the same location.

The most significant difference between the ERT and neutron images is that the volume implied by the ERT image is substantially larger than that implied by the neutron image. We believe that this lack of similarity is caused by the objective function used to solve the ERT inverse problem. This function biases the search towards models having smoothly varying resistivity structures. This means that high resistivity contrasts such as those created by the sodium thio-sulfate are smeared such that the gradient in resistivity values is minimized. Smearing of the values over a wider region is typically the way that the minimum gradients are achieved.

We will now discuss a time sequence of the whole site tomograph shown in Figure 9. This sequence shows the evolution of resistivity change as a function of the volume released. The first two rows of images show the same tomographs displayed using different formats. The top row shows volume renderings of the tomographs where all voxels with ratio values between 1.0 and $0.5\left(10^{0.00}\right.$ to $\left.10^{-0.03}\right)$ shown as transparent. The next row shows horizontal and vertical slices through the image block. The time sequence suggests that the plume moves downward from the release point with relatively little lateral spreading. The second row of images shows evidence of plume development along localized, discrete vertical flow paths or fingers.

Figure 9 also suggests that the plume has penetrated the $12 \mathrm{~m}$ layer by 4/10/01 (the end of spill 2) after 7570 liters of brine. This is much earlier than what is implied by the neutron data. The numerical modeling described previously suggested that any resistivity ratios observed below the $12 \mathrm{~m}$ layer, and smaller than 0.5 (smaller values indicate a larger change) would probably represent true changes in the soil and not vertical smearing of an anomaly above $12 \mathrm{~m}$. The image for $4 / 10 / 01$ is the first image that shows resistivity ratios substantially smaller than 0.5 (approximately 0.25 ). Thus, we believe that this change can be reliably interpreted as an indicator of plume presence. 
The single image at the bottom of Figure 9 shows the resistivity changes caused only by the third spill. In this case, the changes are calculated using data collected on 4/10/01 (just before spill 3 started), and 4/13/01 (the day after spill 3 ended). This image illustrates what happens to the sensitivity to the plume when previous brine spills have dramatically changed the resistivity of the pore fluids. This situation is similar to conditions in the soil surrounding a tank that had previously leaked. The image suggests that while the sensitivity to new plumes is lower, there is still sensitivity to the development of new plumes.

The tomograph at the bottom of Figure 9 suggests that the third spill caused resistivity ratios ranging between 0.5 and 0.6 (resistivity decreased by a factor of 2 approx.). The shape and extent of the plume is similar to those of the other images in the figure, but the magnitude of the changes is a lot smaller. This level of change suggests that it may be possible to detect leaks under tanks even if previous leaks have greatly increased the pore fluid salinity. Based on Figure 3, we suggest that when resistivity decreases by a factor of 2 , the changes can easily be explained as a change in saturation and a change in salinity is not required. Summarizing, the top two rows of images in Figure 9 show resistivity decreases that primarily represent changes in pore fluid salinity; and the bottom image shows resistivity decreases that primarily represent increases in saturation.

\section{Time sequence of $3 D$ images, pie-shaped tomograph}

Our primary purpose in sampling the pie-shaped region was to obtain a detailed time history of plume infiltration. As shown in Figure 1, we used three of the electrode arrays located in the SE quadrant of the site to rapidly sample the region. This part of the site was.selected because past experience indicated that plume infiltration is generally concentrated in this area. The top 10 electrodes in each array were connected to the measurement system to sample depths between 5 and $14 \mathrm{~m}$. Using this arrangement, 3D surveys could be collected every 25 minutes.

Figure 10 shows the time history corresponding to the first spill of sodium thiosulfate. The total volume released was 1916 liters and the spill occurred on 3/30/01. The image on the upper left corner of the figure shows the location of the electrode arrays (vertical, solid white lines), steel casings (vertical, dashed white lines), and the location of the injection point (black vertical arrow). The location of the injection point is approximately $1 \mathrm{~m}$ north (behind) of the back face of the tomograph region. Dashed black parallelograms indicate the location of fine-grained layers at 6 and $12 \mathrm{~m}$. depths. Red colored labels indicate the approximate beginning and ending times for the release.

During the release period (release ended at approximately 13:55), the tomographs show a small resistivity decrease developing near the injection point which grows gradually with time. The bottom of the anomaly is resting on top of the $6 \mathrm{~m}$ fine-grained layer. Approximately two hours after the release ended (15:09) and into the next day, the anomaly penetrates the $6 \mathrm{~m}$ layer and extends a few meters below it. 
The bottom row of images in Figure 10 shows two views of the tomograph from 4/10/01. Between $4 / 3 / 01$ and 4/5/01, an additional 5600 liters were released so that by $4 / 10 / 01$ a total of 7570 liters had been released. Both views of the $4 / 10 / 01$ tomograph suggest that the $6 \mathrm{~m}$ and $12 \mathrm{~m}$ layers have been penetrated. The resistivity has decreased by a factor of 100 (approximately) just below the $6 \mathrm{~m}$ layer. Below the $12 \mathrm{~m}$ layer, the resistivity has decreased by a factor of 10 . The pie-shaped and whole site tomographs corresponding to 4/10/01 (compare Figures 7 and 9) are consistent in that both show the plume extending below the $12 \mathrm{~m}$ layer.

We will next consider the time sequence associated with the third spill of sodium thiosulfate; this sequence is shown in Figure 11. A total of 7570 liters were released during spill 3. One half of the total volume was released on $4 / 11$ and the other half on 4/12/01. Each release episode lasted a few hours. The resistivity changes are relative to data collected on $4 / 11$ just before the spill started. By the time these surveys were taken, the first two spills had already changed the resistivity of the soil in very dramatic way (approx. 100-fold). This means that the changes caused just by the third spill (Figure 11) were significantly smaller than those shown in Figure 10.

During the first day of the spill (4/11), the changes are very small and undetectable given the transparency (sensitivity) level chosen. During the second release (4/12/01), significant changes can be observed. The tomographs suggest that the resistivity has changed $20-30 \%$ at a maximum. The anomaly extends downward from the $6 \mathrm{~m}$ layer, and gradually grows with time and the released volume. The image for 4/13/01 suggests that the anomaly has reached the top of the $12 \mathrm{~m}$ layer.

We believe that the low level of change in Figure 11 indicates that most of the large changes in resistivity developed during the first two spills (3/30/01 and 4/4 -6/01)resulted as the sodium thiosulfate brine mixed with or replaced the native pore water. By the time the third spill was conducted, the bulk of the salinity changes in the pore fluid had already happened. The resistivity changes observed are mainly caused by changes in saturation. The time sequence in Figure 11 illustrates what happens to the sensitivity of the plume when previous brine spills have dramatically changed the resistivity of the pore fluids. This situation is probably similar to conditions in the soil surrounding a tank that has previously leaked. Figure 11 suggests that while the sensitivity to new plumes is lower, there is still sensitivity to the development of new plumes.

We now consider the resistivity changes created by the release of river water (we will refer to this water as "chaser") released at the end of all sodium thio-sulfate spills. We monitored the first two days of the chaser spill (5/2 and 5/3/01) during which time 7570 liters were released. During the first day, surface samples of the chaser water indicated that the electrical resistivity of the chaser water was somewhat lower $(0.2 \mathrm{ohm}-\mathrm{m})$ than that of the concentrated brine $(0.3 \mathrm{ohm}-\mathrm{m})$. The reason for the decreased resistivity 
appears to be that the river water was poured into the tank previously containing sodium thiosulfate; salt sludge at the bottom of the tank mixed with the river water to decrease its electrical resistivity. Even though the salt concentration was higher in the full- strength brine, the resistivity actually dropped upon dilution because the relationship between concentration and electrical resistivity is non- linear. Near the end of $5 / 2$ (at about 14:00) and during all of $5 / 3$, the river water used came from a clean tank and samples of water from this tank indicated that the resistivity was much higher $(70 \mathrm{ohm}-\mathrm{m})$.

Figure 12 shows the tomographs of resistivity change corresponding to the chaser water release. The changes are relative to the resistivity measured on 5/1/01, prior to the start of chaser release. The top row of images shows the changes during the first day $(5 / 2 / 01)$ when the chaser water still has some salt. The bottom row of images shows the changes during the second day when fresh water was used. The color scale used in this figure represents a much narrower range of values than for any of the color scales associated with previously discussed figures. The color scale in the figure indicates that the resistivity changes (both increases and decreases) by about a factor of 3 .

The first row of images in Figure 12 indicates that the resistivity of the soil decreased during the first day $(5 / 2 / 01)$. This development was expected because the resistivity of the chaser water was lower than that of the full strength brine. After 322 liters have been released, the decreases are only seen above the $6 \mathrm{~m}$ layer. After 1105 liters, there are two distinct zones of decreases: one near the $6 \mathrm{~m}$ layer and a new zone extending down to the $12 \mathrm{~m}$ layer. The image corresponding to 2630 liters suggests that the two zones are now connected and forming a single body extending from 5 to $14 \mathrm{~m}$ depth.

The second row of images in Figure 12 shows both increases and decreases in resistivity. This row of images shows the changes during the second day (5/3/01) when fresh water was used. There are significant resistivity increases along the front (South) face of the block and along the $12 \mathrm{~m}$ layer. The resistivity increases form finger-like structures that surrounds the zone of decreased resistivity that developed previous spills. These fingers grow in extent and magnitude as additional fresh water is released. After 7570 liters have been released, the resistivity increases form a single, continuous finger that partially surrounds the zone of resistivity decreases. Note that the resistive finger connects to the release point location. These zones of increasing resistivity could be caused by two mechanisms: (1) The river water is more than twice as resistive as native pore water (see Figure 3). Additionally, because the brine has a high surface tension, the river water will not displace it but rather flow around (over the surface of) the existing brine plume. Therefore, the resistivity increases could be a result of the infiltration water displacing the native pore surrounding the brine plume. (2) Mixing of the river water and brine will change its resistivity in a complex way. Initial dilution of the brine will actually increase its electrical conductivity (this effect we observed during the field test from electrical measurements on samples of the brine and river water). However, with continued dilution the brine conductivity will eventually decrease. Therefore, the resistivity 
increases could also be a result of excessive dilution of the brine pore fluid as the river water flows over the surface of the existing brine plume.

These tomographs suggest that when high ionic strength water (.i.e., highly concentrated sodium thio-sulfate brine) is filling the pore spaces, low ionic strength water will not displace it. Instead, the low ionic strength water finds pathways around the brine plume. One reason for this maybe that the high ionic strength brine has elevated surface tension that tends to keep the brine in the pores (Ward, A. and Gee, G., 2001).

Resistivity changes caused by low and high ionic strength fluids: comparison of FYOO and FY 01 tomographs

We now wish to compare the changes caused by infiltration of fluids having different ionic strengths. In FY00, most of the releases at the Sisson and $\mathrm{Lu}$ site consisted of low ionic strength river water (resistivity of $70 \mathrm{ohm}-\mathrm{m}$ - low ionic strength). The water released during the first two spills infiltrated soil partially saturated with low ionic strength solution (estimated at $30 \mathrm{ohm}-\mathrm{m}$ ). The third spill in FY00 released a potassium bromide $(\mathrm{KBr})$ tracer with a resistivity of $4 \mathrm{ohm}-\mathrm{m}$ (moderate ionic strength). The $\mathrm{KBr}$ tracer invaded soil that had previously received 7900 liters of $70 \mathrm{ohm}-\mathrm{m}$ water. In contrast, the first five spills of FY01 released high ionic strength river water (resistivity of $0.3 \mathrm{ohm}-\mathrm{m}$ ); the first two spills infiltrated soil partially saturated with with low ionic strength solution (estimated at $70 \mathrm{ohm}-\mathrm{m}$ ).

Figure 13 compares resistivity change observed during the FY 00 and FY 01 experiments. The top row of images compares the changes caused by similar volumes of released fluids having vastly different ionic strengths. It is somewhat tricky to compare these two images because they display widely different resistivity changes. This means that the level of smoothing caused by the inverse algorithm is quite different in the two cases, making the plume dimensions difficult to compare.

The top left image image illustrates the changes observed when $70 \mathrm{ohm}-\mathrm{m}$ river water infiltrated soil partially filled with natural pore water (estimated at $30 \mathrm{ohm}-\mathrm{m}$ ) during FY00. Resistivity decreased by about a factor of $2-3$ in this case. Based on the curves in Figure 3, we suggest that the dominant effect that caused the resistivity to drop was an increase in the saturation of the soil; the effect of fluid salinity change is relatively minor. Note that the plume extends from 6 to about $12 \mathrm{~m}$ depth. There is no penetration of the $12 \mathrm{~m}$. layer and no evidence of fingering, The bowl-shaped plume suggests both lateral and vertical movement of the fluid.

The top right image in Figure 13 image illustrates the changes observed when $0.3 \mathrm{ohm}-\mathrm{m}$ solution (highly concentrated sodium thio-sulfate) infiltrated soil partially filled with native pore water (estimated at $30 \mathrm{ohm}-\mathrm{m}$ ). Resistivity decreased by about a factor of 10 - 100 in this case. Based on the curves in Figure 3, we suggest that the dominant effect 
that caused the resistivity to drop is a dramatic increase in pore fluid salinity; the effect of fluid saturation change is relatively minor. The plume now begins at $5 \mathrm{~m}$ and extends past the $12 \mathrm{~m}$ fine-grained layer all the way to $19 \mathrm{~m}$ depth. The columnar shape of the plume suggests that the fluid is moving straight down. There is also evidence of vertical fingering.

Comparing the top two images in Figure 13, it is clear that there are significant differences in plume migration when fluids of different ionic strengths are used. The plume's vertical extent is longer for the high ionic strength fluid while the low ionic strength fluid shows more lateral extent. The time required to reach the bottom of the volume shown is shorter for the high ionic strength fluid. Also, discrete, localized, vertical flow paths (fingers) can be observed for the high ionic strength fluid but not for the low ionic strength fluid.

The lower row of images in Figure 13 compares FY 00 and FY 01 tomographs showing approximately the same magnitude of resistivity decrease (factor of about $30 \%$ ). By comparing these tomographs, we minimize the uncertainty in estimates of plume dimensions associated with comparisons of tomographs showing vastly different resistivity changes. The bottom left image shows the changes in resistivity caused by the $\mathrm{KBr}$ spill in FY00. This result indicates what happens when a low ionic strength tracer infiltrates a soil that is very wet due a release of 7900 liters of fresh water (very low ionic strength) the week before. In this case, the observed resistivity change is caused by changes in pore fluid salinity and by changes in saturation. The $\mathrm{KBr}$ spill created a bowlshaped region that extended from 5 to about $9 \mathrm{~m}$, and the maximum width of the plume is about $7 \mathrm{~m}$ in the North-South and East-West directions. The shape of the plume suggests both lateral and vertical development of the plume.

The bottom right image shows the changes in resistivity caused by the third sodium thiosulfate spill in FY01. This result indicates what happens when a high ionic strength solution infiltrates a soil that is very wet due a previous release of 7570 liters high ionic strength solution the week before. In this case, the observed resistivity change is caused primarily by changes in saturation. The addition of 3875 liters of solution creates a fingershaped, vertically oriented region that extends from 5 to about $12 \mathrm{~m}$, and the maximum width of the plume is about $7 \mathrm{~m}$ in the North-South direction and $3 \mathrm{~m}$ in the East-West direction. The shape of the plume suggests the primary flow direction is downward.

The bottom row of images in Figure 13 suggests that the low ionic strength plume shows more lateral spreading and less vertical spreading than the high ionic strength plume. The shape of the low ionic strength plume does not suggest that there are preferential pathways. The shape of the high ionic strength plume suggests the primary flow direction is downward along a localized, preferential pathway.

\section{Possible tank farm deployment scenarios:}




\section{Using existing steel casings as electrodes}

Monitoring for leaks and plume movement under tank farms is a problem of interest to DOE. If one could easily and cheaply drill boreholes around existing tanks, monitoring for leaks and plume movement using ERT would be relatively straightforward and has been demonstrated as described by Ramirez ET. al (1996). A key problem implementing this approach, is the cost (and risk) of drilling boreholes within a tank farm. Here we consider other possible deployment scenarios that do not require drilling within a tank farm, and test their effectiveness using data from the infiltration tests.

The simplest and cheapest tank farm deployment scenario would involve the installation of electrodes only at the ground surface. In many situations, this arrangement has been shown to be useful. However, in a tank farm, surface electrodes are unlikely to be useful for the following reasons. The metal tanks are $75 \mathrm{ft}$ in diameter, $50 \mathrm{ft}$. tall and are very good electrical conductors. If electrodes are placed at the surface, currents will be channeled into the tanks themselves; little, if any, current will reach below the tanks. This will greatly reduce sensitivity under the tanks. The distance between adjacent tanks (usually about $25 \mathrm{ft}$.) is small compared to a tank's diameter. Therefore, moving electrodes away from a tank in order to get some of the current to sample the soil below the tank will only move those electrodes closer to adjacent tanks. As a result, it is very difficult to sample the soil below the tanks using surface electrodes.

Successful ERT below a tank farm requires the ability to inject significant current below the tanks. One option which does not require additional drilling is to use the steel casings of the so called "dry wells" as (long) electrodes. Around each tank there are usually several steel cased boreholes that extend below the tank bottom. By connecting a wire to each of them at the ground surface, it is possible to direct a small amount of current beneath the tanks. This approach would only allow low resolution (there are few casings around each tank) horizontally and little or no resolution vertically (currents are predominately horizontal). To demonstrate this principle we have used the steel casings at the Sisson and Lu site as surrogates for the dry wells.

Another scenario that we have considered is a logical extension of the "long" electrode approach described above. In this case, we assume that boreholes can be drilled some distance away from the tank farm perimeter (perhaps outside of the fence) and that vertical electrode arrays are installed in them. The vertical electrode arrays are then used in combination with the steel-cased dry wells to sample the soil around and underneath the tank farms. This approach offers the possibility of resolving plumes vertically as well as horizontally.

On $3 / 25 / 01$, a baseline data set was collected using 30 of the steel cased boreholes as long electrodes. During the spill sequence, the long electrode surveys were repeated at various times to monitor the time history of the plume. We successfully reconstructed values of 
transfer resistance $R_{D}$ measured after each release, using equation (1) in exactly the same way as described above. The only change in the approach was that each casing was modeled in the 3D finite difference mesh as an increased conductance line along a column of nodes. These conductances were $10^{4}$ times larger than the conductances elsewhere on the mesh.

The long electrode results for spills 1 and 2 combined are shown in Figure 14. The image on the left is a tomograph of the whole test site, using data measured with all eleven point electrode arrays; this tomograph is presented as a point of reference. The rightmost image is a tomograph calculated using only data from long electrode surveys; this arrangement is similar to using the dry wells around the tanks as long electrodes. The image in the middle used data from combined point and long electrode surveys: data collected with the 120 point electrodes located in eight arrays along the perimeter of the site is combined with the long electrode data. In the combined data set, measurements using electrodes in the interior arrays were removed to simulate the case were no electrode arrays are installed within a tank farm. This approach is similar to what could be done if electrode arrays were installed outside the farm's perimeter and the "dry wells" were used as electrodes inside the farm.

The long electrode images yield useful results. Notice that the anomaly images are located at the top of the image block for the middle and rightmost images. The vertical extent for the anomaly in the rightmost image anomaly is artificial-it does not represent the actual depth extent of the plume-but rather is controlled by the value set in the finite element mesh for the conductivity of the steel casings. The vertical extent for the anomaly in the center image anomaly is real because the data collected with the point electrode arrays provides vertical resolution.

Both long electrode images show a conducting anomaly, correctly representing the horizontal location of the tracer water plume, directly below the release point. Because of the crude sampling of the image volume using electrodes that are as long as the image block is deep, only a crude image of the plume should be expected. We believe these images demonstrate that steel casings can be used to detect the presence of leaks and also to produce maps of the horizontal location of plumes under tanks when the dry wells are used as long electrodes.

If vertical electrode arrays are installed around the perimeter of a tank farm and are used in combination with the "dry wells", it should be possible to produce maps of the vertical and horizontal location of plumes underneath a tank farm.

\section{Fast 3D tomographs to obtain results in the field:}

We are currently exploring ways in which ERT data can be displayed rapidly, in image form, thus allowing on-site examination of results. Although such methods will not replace the more rigorous means of determining images (i.e. the iterative inverse method 
described earlier), on-site imaging will allow the following. (a) Calculation of a tomograph will be completed seconds after the data survey is completed, thereby allowing identification of possible leaks very quickly. (b) Evaluation of data quality and consistency can be performed quickly, thereby allowing steps to be taken to adjust the surveys there and then, if required. (c) Quickly identify data sets that are indicative of leakage so that these data can be processed using the iterative inverse method. Although substantially slower, the iterative inverse method yields more reliable and quantitative images for leak detection. This combination of qualitative and quantitative solutions will save valuable computer time and yield results quickly.

We need techniques that may be viewed as equivalent to plotting pseudo-sections of apparent resistivity, which are used widely in conventional surface resistivity surveying. For arbitrary electrode geometry and measurement schemes pseudo-sections are not appropriate. However, use may be made of techniques established in bio-medial electrical imaging. These methods are often referred to as qualitative, rather than quantitative (an example of which is the method we are about to describe).

These qualitative bio-medical tools are suitable for displaying images containing small contrasts in resistivity and thus would normally not be useable for general subsurface problems as variation over a few orders of magnitude is typical in ERT problems. However, these tools may be useful for studying time-lapse data where a sequence of data sets should reveal a change in the electrical properties and these changes are likely to be much smaller than the range of values in the background state.

For illustration we show some of the results of using the method of Kotre $(1989,1994)$ in Figure 15 and compare with results using the iterative inverse approach. With this approach, a voxel parameter value $P$ is determined as

$$
P_{i}=\frac{\sum_{j=1}^{N} I_{i j}\left(\ln \left(T_{j}^{t}\right)-\ln \left(T_{j}^{0}\right)\right)}{\sum_{j=1}^{N}\left|J_{i j}\right|}, \quad(i=1,2, \ldots, M)
$$

where $J_{i j}$ is the sensitivity (or Jacobian) matrix as used in the normal ERT inversion process, $T_{j}^{0}$ is the measured transfer resistances at some background state, $T_{j}^{t}$ is the measured transfer resistances after some process, $N$ is the number of measurements, and $M$ is the number of parameters (voxels in image).

Figure 15 shows that changes due to the brine release can be seen clearly and there is a degree of correspondence between the results from the qualitative method and our conventional, more rigorous, quantitative approach. We do not see the simpler one-pass 
type approach as a replacement for the rigorous inversion procedure normally adopted but as a means of displaying changes in resistivity rapidly on-site.

\section{Summary and Conclusions:}

From the work in FY01 we can draw conclusions about both the attributes of ERT and about the physical response of the subsurface during the experiment. We conclude the following about the attributes of ERT:

ERT will produce reliable results at the site when the effects of the many steel casings are properly modeled. Steel casings act as significant electrical shunts that affect the resolution of all electrical methods, especially in the vertical direction. Numerical modeling results suggest that the net effect of the casings is to "smear" the anomalies in the vertical direction. This effect is strongest near the center of the pattern, where multiple steel casings are in close proximity. The casings' shunting effect gets stronger as the conductivity of the brine increases. The models suggest that significant vertical smearing is present in the whole site tomographs that used all electrode arrays. The tomographs of the relatively smaller pie-shaped region are much less affected by the shunting effect. We have accounted for the shunting effect by considering as reliable plume indicators those resistivity changes that are above a threshold set on the basis of numerical modeling.

Using a simple model based on Archie's equation, we have estimated the relative contributions of saturation and pore fluid resistivity change to the measured change in electrical resistivity. When highly concentrated brine is injected, the model suggests that almost all of the change in electrical resistivity (factor of about 200) is due to changes in pore fluid resistivity. In contrast, changes in saturation only change the resistivity by factors of 4 to 5 . This means that electrical resistivity can change a large amount even when the saturation of the region changes a small amount.

The following conclusions can be reached based on interpretations of the field tomographs:

- The highly concentrated brine tends to move straight down and tends to produce vertical, localized, preferential pathways ("fingers") as it does. When concentrated brine is released, there is less lateral spreading of the plume when compared to plumes of relatively fresh water.

- The tomographs suggest that the fine-grained layers located at 6 and $12 \mathrm{~m}$ depths are penetrated by the brine. There is some level of uncertainty in this interpretation because of the reduced vertical resolution caused by the casings' shunting effect. The inferred penetration of the $12 \mathrm{~m}$ layer is credible because the magnitude of the signal 
below the layer is significantly larger than the numerical predictions of "smearing" associated with the steel casings.

- The resistivity change tomographs compare reasonably well with neutron differences that show the brine plume contained above the $12 \mathrm{~m}$ layer. The location and general size of the ERT and neutron results are similar. The tomographs suggest a strong, well-developed finger that penetrates the below the $12 \mathrm{~m}$ layer in the vicinity of boreholes $\mathrm{H} 4$ and $\mathrm{H} 6$. Neutron surveys taken after all the spills were concluded indicate a region of increased saturation in this area. However, the tomographs suggest penetration of the $12 \mathrm{~m}$. layer well before it is detected by neutron surveys. Possibly, an incipient finger formed relatively early below the $12 \mathrm{~m}$ layer thereby creating large conductivity increases but small changes in saturation. A tomograph will primarily detect a change in the pore fluid electrical conductivity while the neutron surveys detect a saturation change. The electrical conductivity changes by a factor of approximately 200 while the saturation changes by a factor of 4 to 5 . This means that the tomographs are 50 times more sensitive to small, localized penetrations of the brine.

- Some of the tomographs suggest that the anomaly associated with the plume gets weaker in the vicinity of the 6 and $12 \mathrm{~m}$ layers. A possible explanation for this observation is that perched water on top of these fine-grained layers dilutes the brine, thereby reducing the electrical resistivity changes observed in the tomographs.

- Resistivity changes created by the fresh water released after the brine spills suggest that the fresh water forms fingers that follow pathways around the brine plume without penetrating the brine plume itself.

$-$

- We are developing promising inverse approaches that offer the capability of fast processing of ERT data using standard laptop computers. This means that, if the techniques can be proven to be reliable, qualitative 3D tomographs can be calculated in the field within a few minutes of data collection.

- The steel cased "dry wells" can be used as long electrodes to produce images of good resolution. Images calculated using long electrode data indicate that there is good sensitivity to the plume and good lateral resolution. Vertical resolution is not available with this approach. Vertical resolution can be achieved when vertical electrode arrays are installed around the perimeter of a tank farm and are used in combination with the "dry wells". 


\section{REFERENCES:}

Daily, W. D., A. Ramirez and R. Johnson, 1998, Electrical impedance tomography of a perchloroethelyne release, J. Envir. and Eng. Geophysics, vol. 2, No. 3, pp. 189-201.

Henderson, R.P., and Webster, J.G., 1978, An impedance camera for spatially specific measurements of thorax, IEEE Trans. Biomed Eng., BME 25, 250-254.

LaBrecque, D. J., M. Miletto, W. Daily, A. Ramirez, and E. Owen, 1996, The effects of Noise on Occam's Inversion of Resistivity Tomography Data, Geophysics, vol. 61, no. 2,.pp. 538-548.

LaBrecque, D. J., A. Ramirez, W. Daily, A. Binley and S. Schima, 1996, ERT Monitoring of Enviromental Remediation Processes, Meas. Sci. Technol., vol. 7, .pp. 375-383.

Kotre, C.J., 1989, A sensitivity coefficient method for the reconstruction of electrical impedance tomograms, Clin. Phys. Physiol. Meas., 10, 275-281.

LaBrecque, D., Morelli, G., Daily, W., Ramirez, A., and Lundegard, P., 1999, Occam's inversion of 3D electrical resistivity tomography, in Oristaglio M., and B. Spies, Eds., Three Dimensional Electromagnetics,: Soc. Expl.Geophys.

Lytle, R.J., and K. Dines, 1978, An impedance camera: A system for determining the spatial variation of electrical conductivity, Lawrence Livermore Laboratory, Livermore CA, UCRL-52413.

Kotre, C.J., 1994, EIT Image reconstruction using sensitivity weighted filtered backprojection, Physiol. Meas., 15 (Suppl. 2A), 125-136.

Ramirez, A., W. Daily, K. LaBrecque, E. Owen and D. Chesnut, Monitoring an Underground Steam Injection Process Using Electrical Resistance Tomography, Water Resources Research, vol 29, no. 1, 1993

Ramirez, A., W. Daily, A. Binley, D. LaBrecque, and D. Roelant, 1996, Detection of leaks in underground storage tanks using electrical resistance methods, Journal of Environmental and Engineering Geophysics, Vol. 1, no. 3, 189-203.

Ward, A., and G. Glendon, 2001, Vadose Zone Transport Field Study, FY 2001 Test Plan, PNNL-13451, Rev. 1, Pacific Northwest National Lab., Richland, Washington. 
Acknowledgments:

The authors wish to acknowledge the contributions of various individuals and organizations that provide valuable assistance and resources. Todd Caldwell (PNNL) collected the neutron data and provided valuable assistance during the ERT surveys. Glendon Gee (PNNL) provided planning guidance and valuable insights on expected plume behavior.

Work performed under the auspices of the U.S. Department of Energy by the Lawrence Livermore National Laboratory under Contract W-7405-Eng-48. 
FIGURES: 

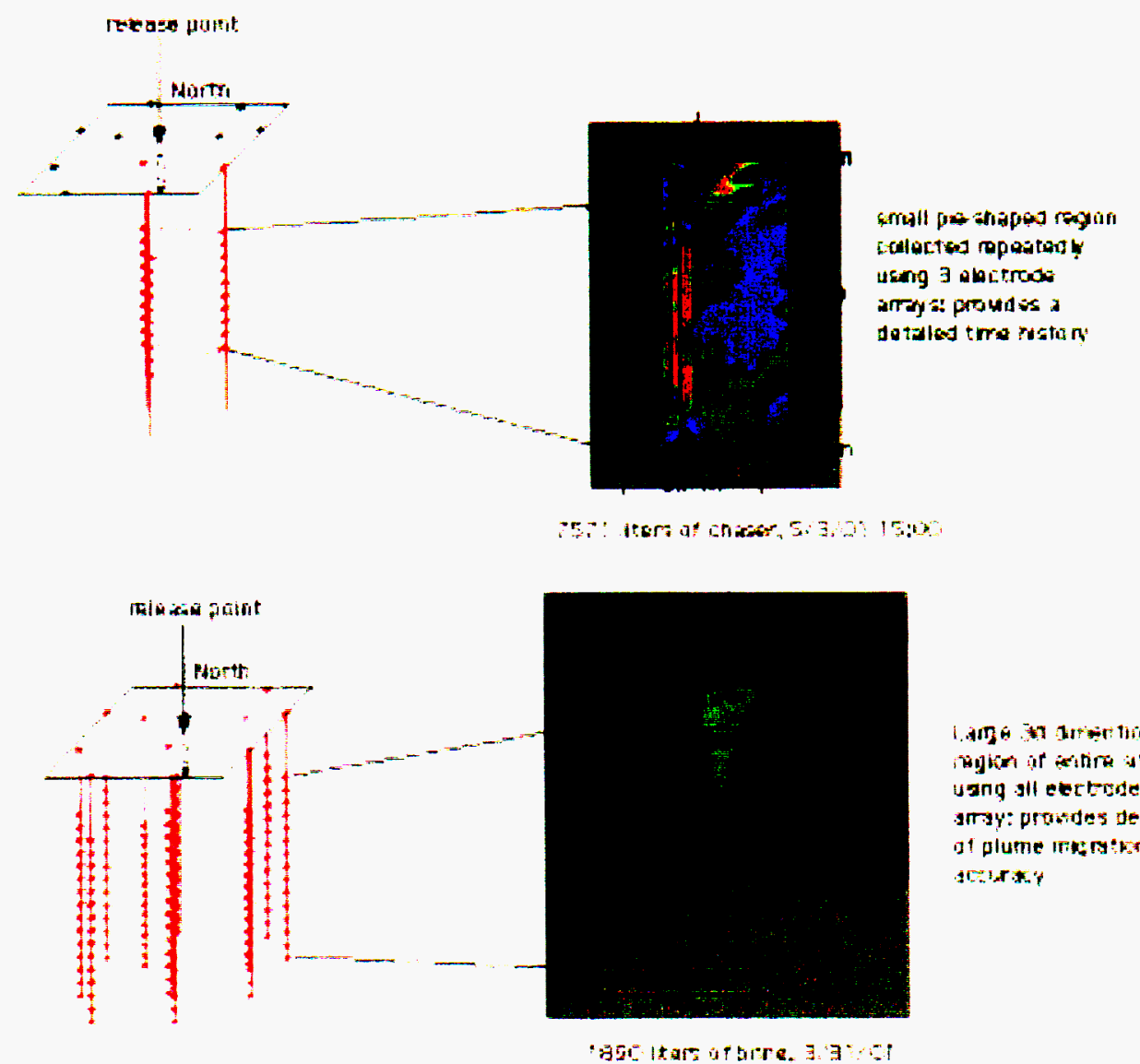

l.ang an arterine inglon at stirn ate uang sll eertorde andy: protodes detsio

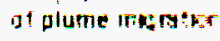
achas

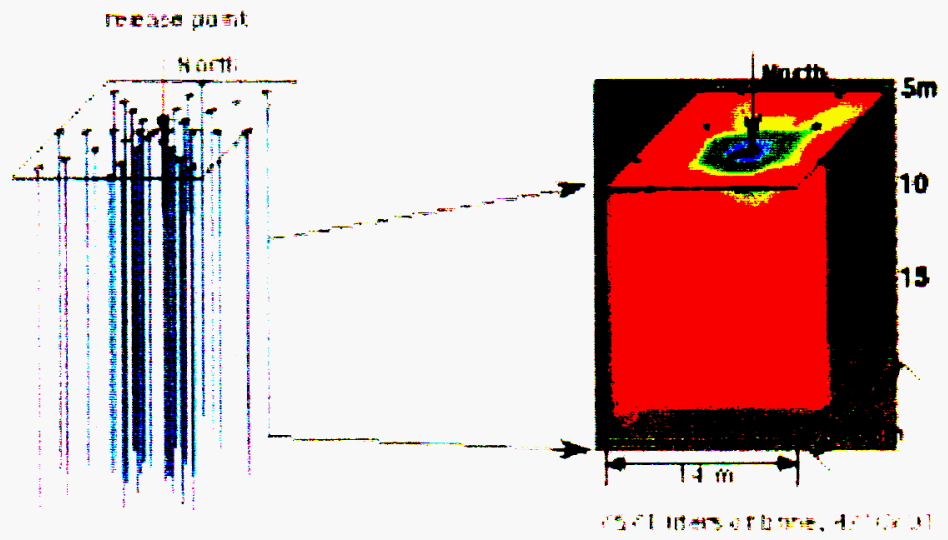

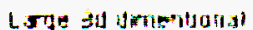
requar $.3 \mid$ sitime sle:

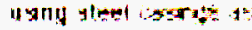

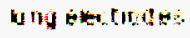

Figure 1. Three perspective views of the site showing the three types electrode arrangements used to survey the site. 
Spills 1 - 5: sodium thio sulfate solution released; spill 6: fresh water chaser

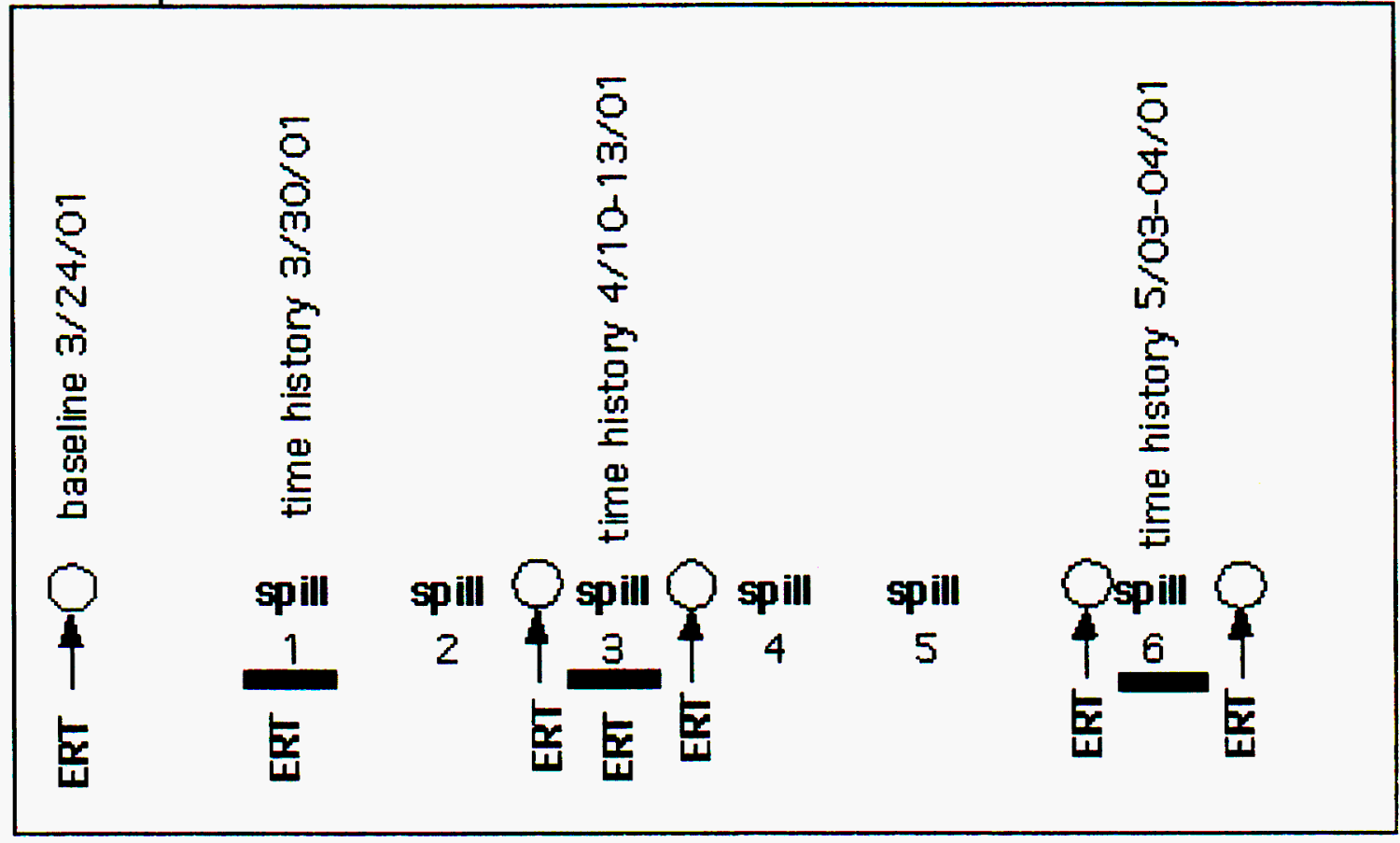

- 3D detailed time history collected on pie-shaped region

† 30 surveys of whole site using all electrode arrays

$(3 D$ surveys of whole site using casings as long electrodes

Figure 2. Schematic time line showing when ERT surveys were collected during the spill sequence. Spills 1 through 5 released a high ionic strength sodium thio-sulfate brine. During spill 6, low ionic strength river water was released . 


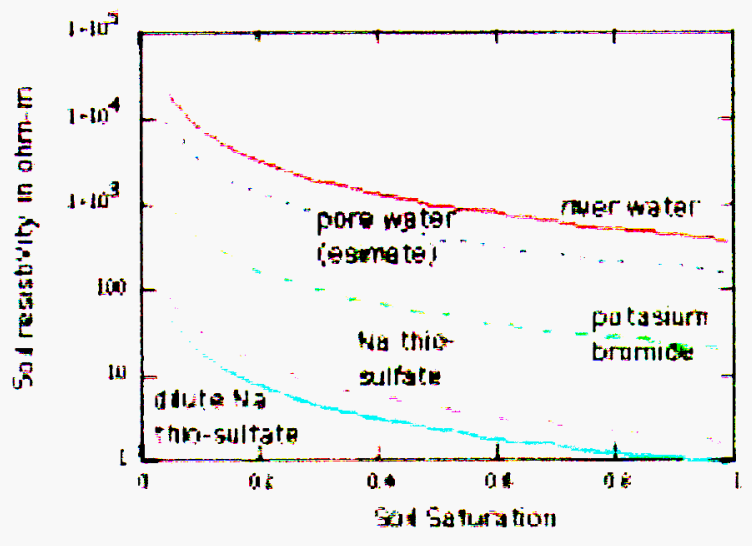

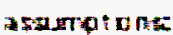

1) Artrege aquation is wald ira gurace cerductance!

3) pomaty - 2.3

3i gaturation esponent $=1.3$

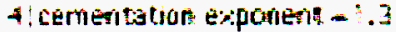

5 iner water - 7o uhrn-m irneasured!

sinatural pore ater - 30 ahrn-th iscumedi

"| pot assam bromide soliaton - 4 onre Tine stures?

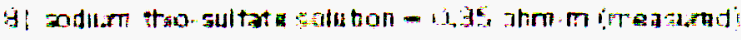

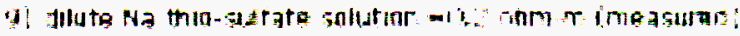

Archie's equation: $\rho_{i}-\phi^{\prime \prime} S^{L \prime} \rho$

$\rho$ bulk resistivity $\$$-saturation

- porosity o water resistivity

Figure 3. Estimates of the bulk resistivity of the soil as function of pore fluid resistivity and saturation. The estimates were calculated using Archie s equation. 

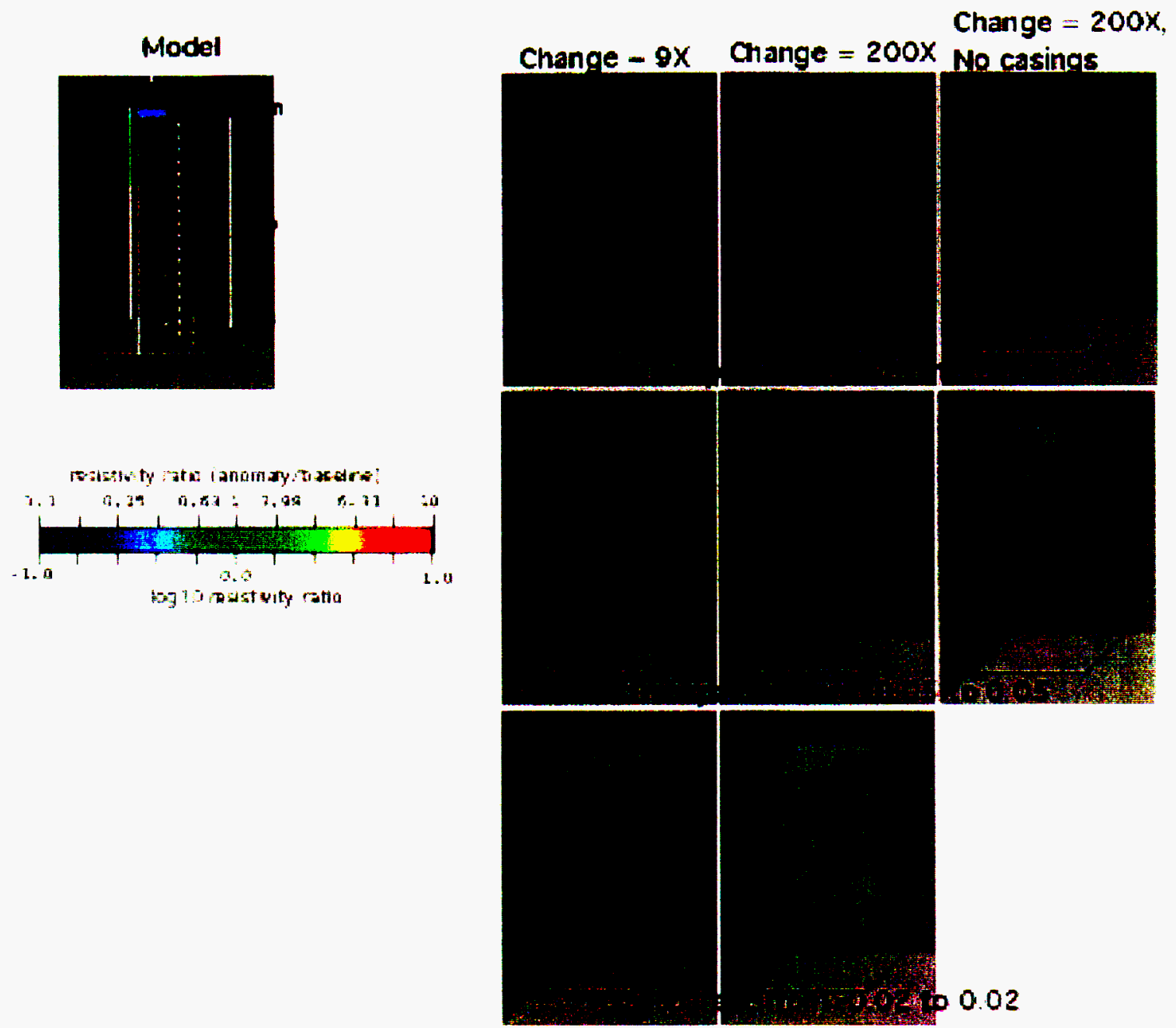

Figure 4. Numerical model results for the pie shaped region. This results illustrate the electrical shunting effects of steel casings. Nine and two-hundred fold decreases in resistivity were considered. Various transparency levels are used to display the $3 \mathrm{D}$ results. 


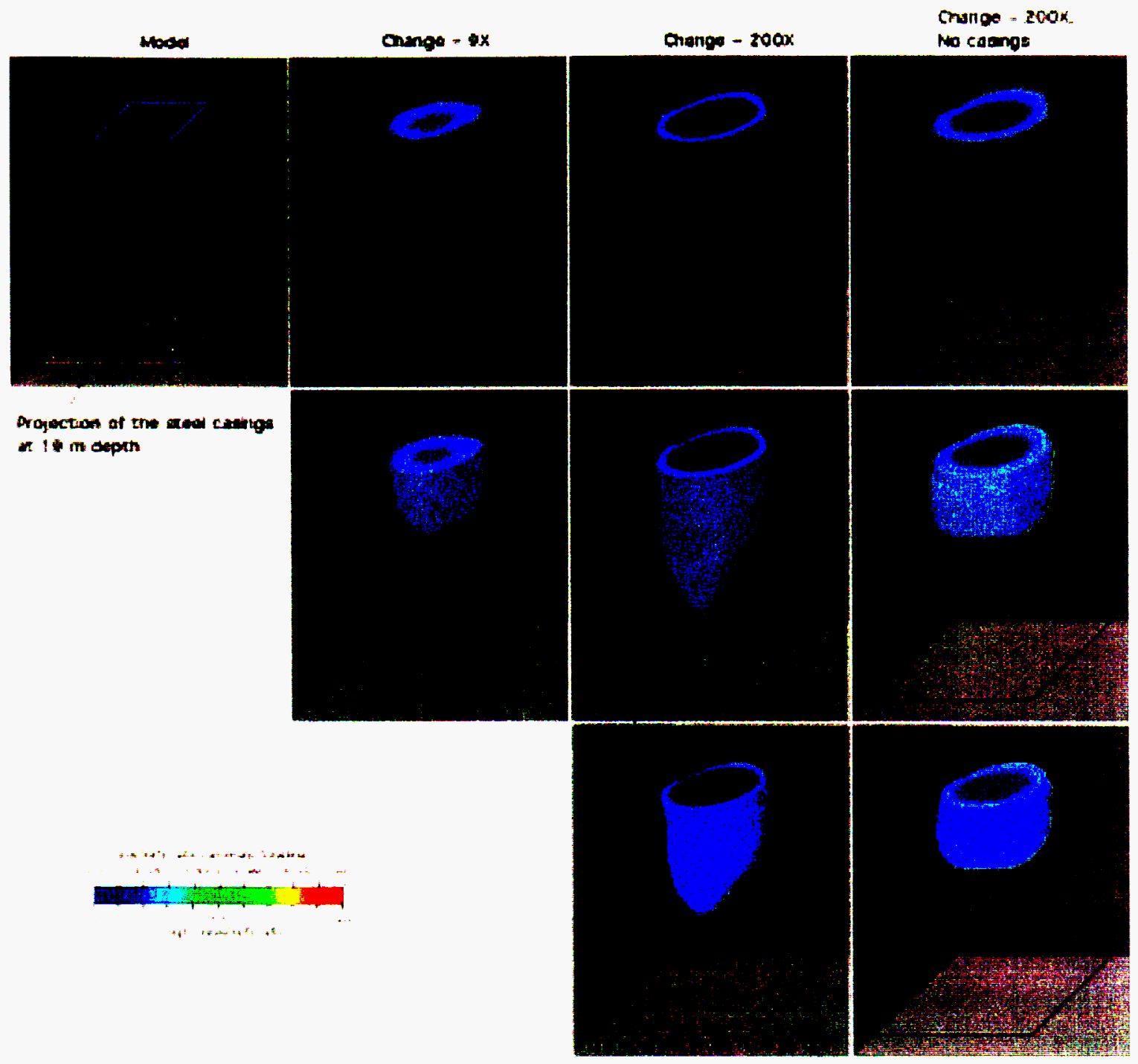

Figure 5. Numerical model results for the whole test site were used to investigate the electrical shunting effects of steel casings. Nine and two-hundred fold decreases in resistivity were considered. Various transparency levels are used to display the 3D results. The projection of the steel casings at $19 \mathrm{~m}$ depth is also shown. 
1890 liters, $3 / 31 / 01$

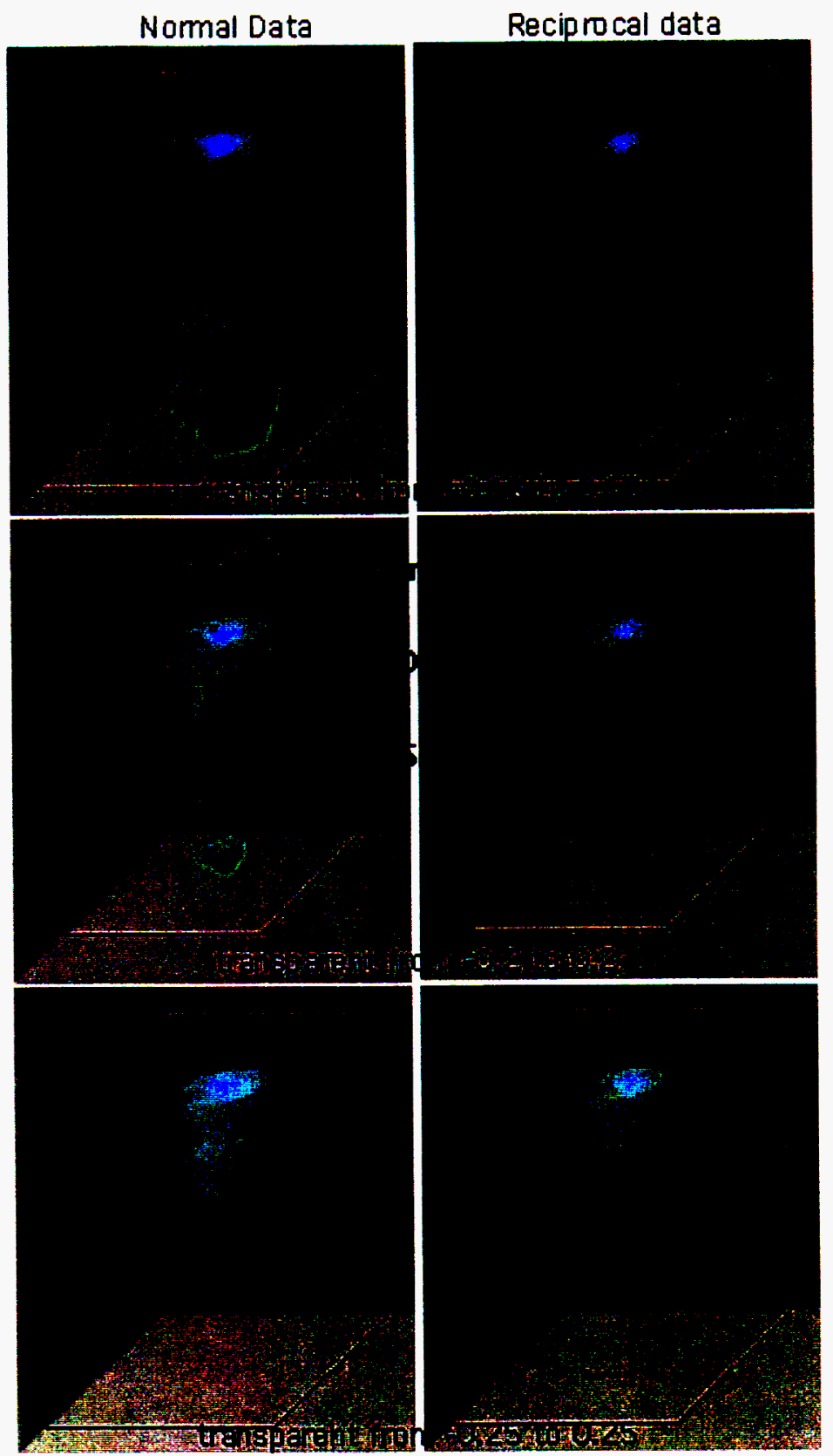

resis tivity ratio (anomaly/baseline)

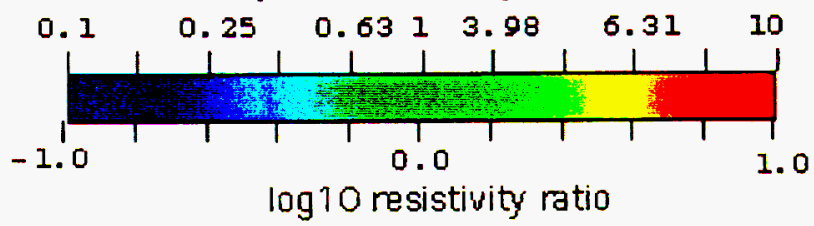

Figure 6. Comparison of images calculated using normal and reciprocal data. Differences between the images in a given row are caused by the influence of measurement error. This approach is useful when evaluating the possibility of false positives. 


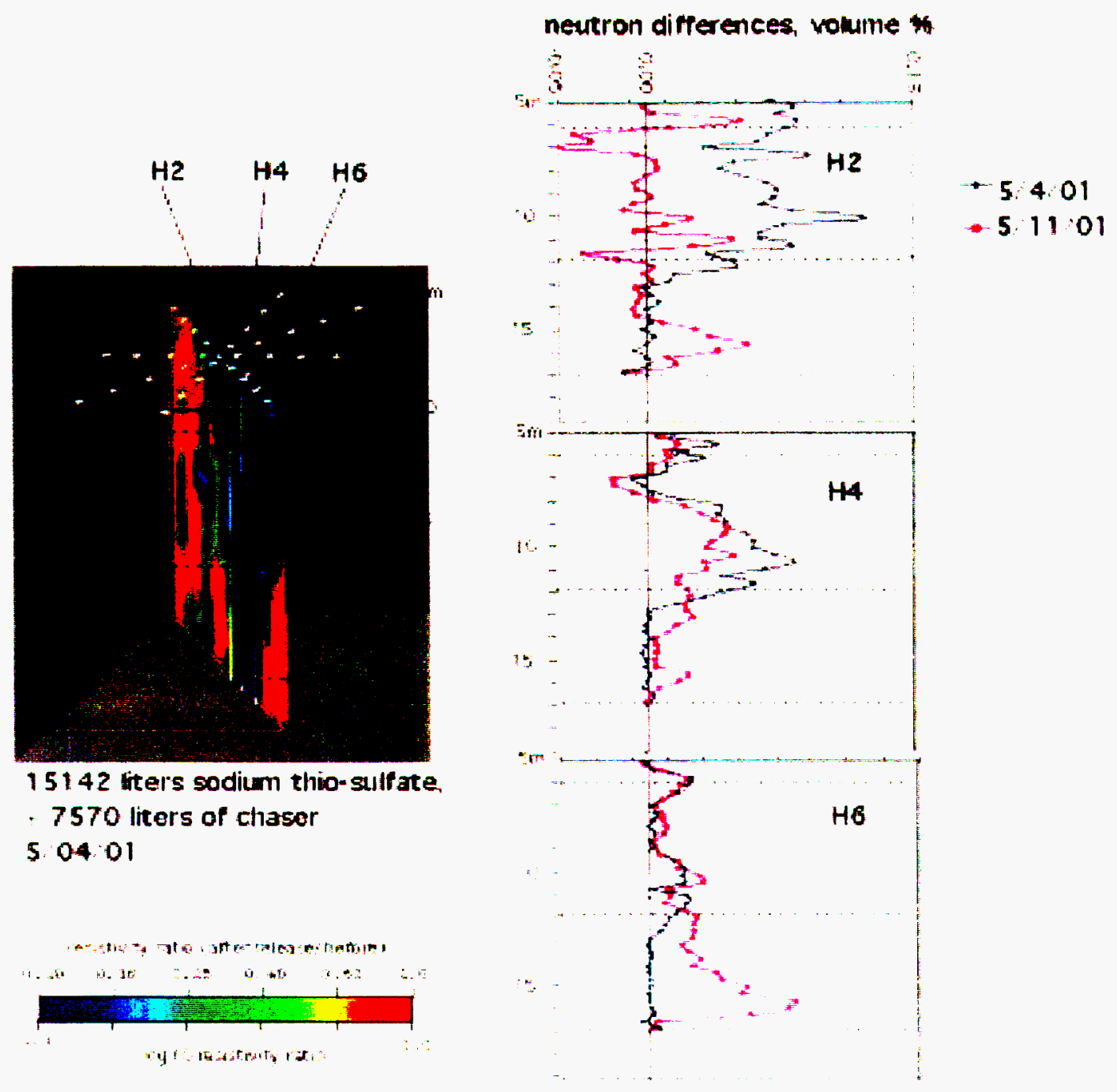

Figure 7. Comparison of a tomograph of the whole test site with neutron log differences along boreholes $\mathrm{H} 2, \mathrm{H} 4$ and $\mathrm{H} 6$. 

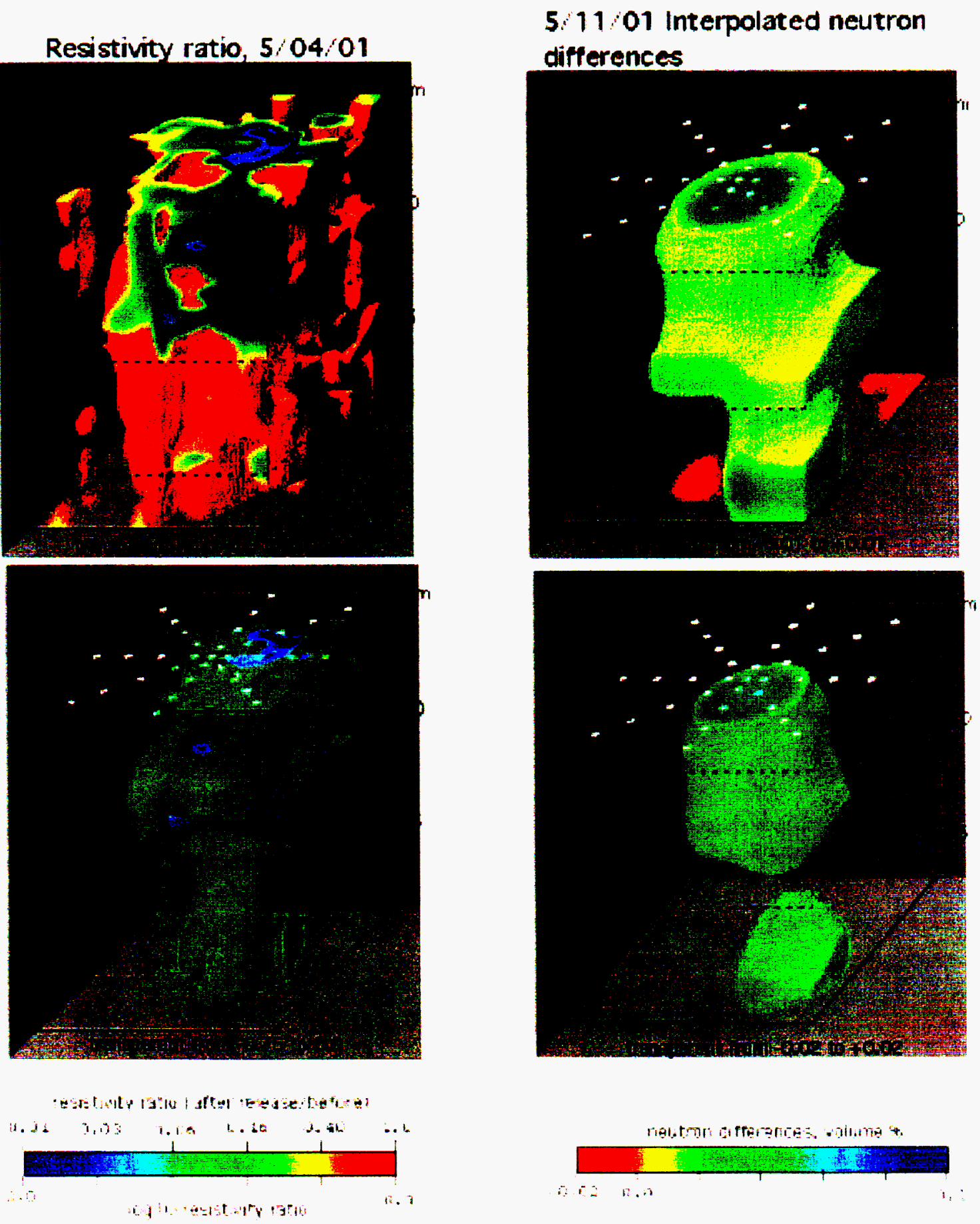

Figure 8. Comparison of a tomograph of the whole test site with a volume rendering of all neutron differences from $5 / 11 / 01$. Linear interpolation was used to create the volume rendering of the neutron data. 

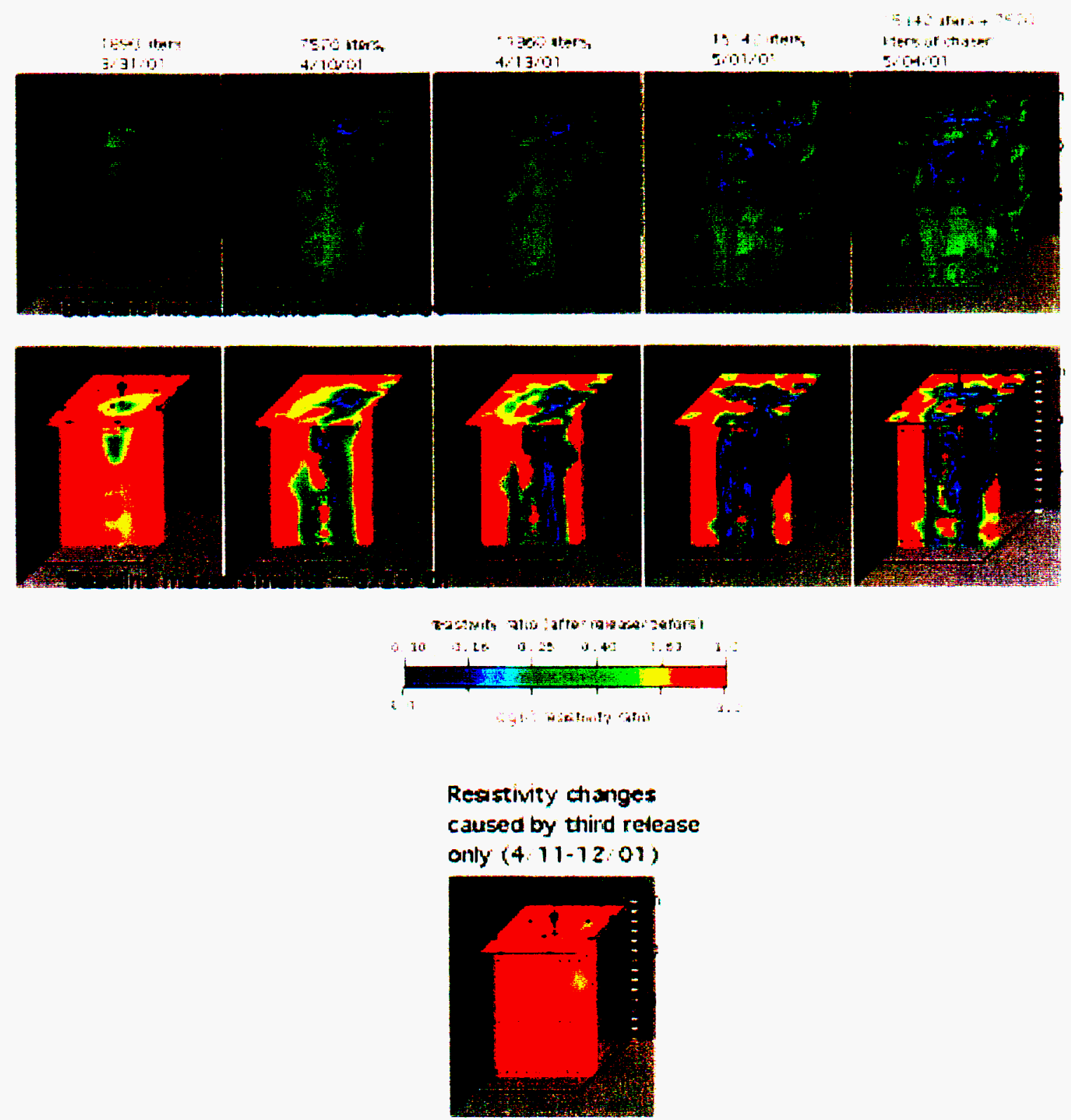

Baseline measurements

410.01

Figure 9. Changes in resistivity of the whole test region as a function time and released volume. Each column along the top two rows shows the same results using a different display format. 


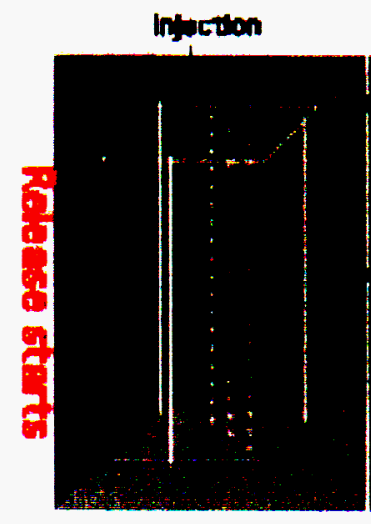

Escilters.

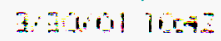

390 ters

- 461,1 : $11: 25$

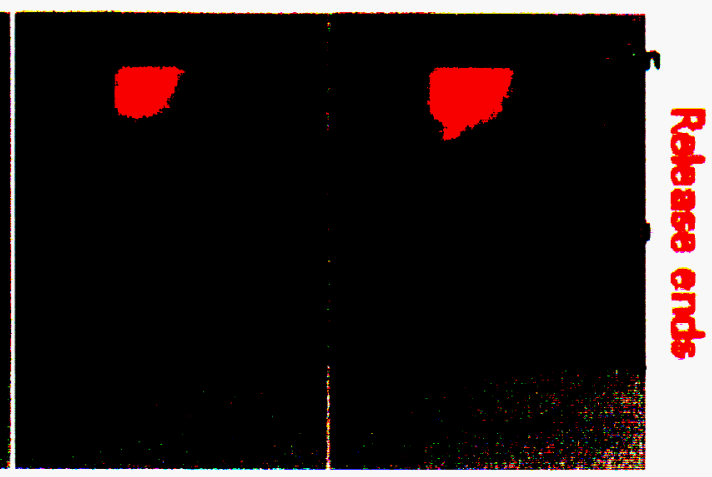

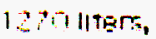

3. 3101020
1500110 ers. 1) $35 \cdot 9 \cdot 2:=$

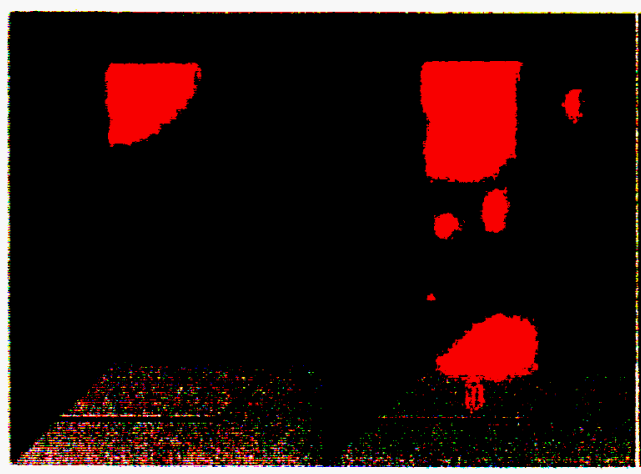

$10:$ intel:. and औरता
916 inarz 5. 30.0. 10:19

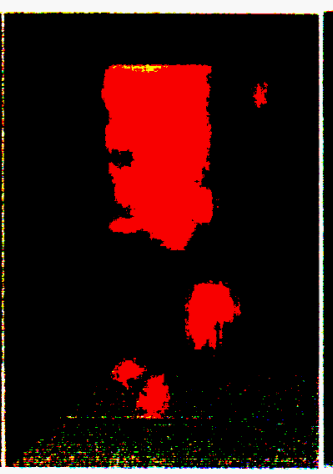

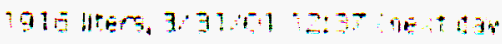

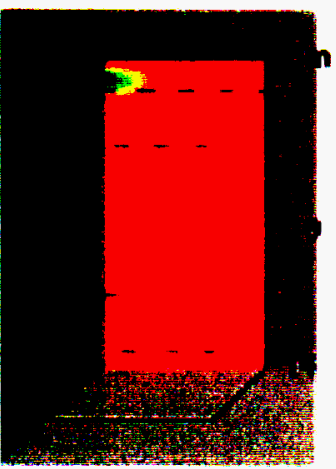

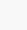
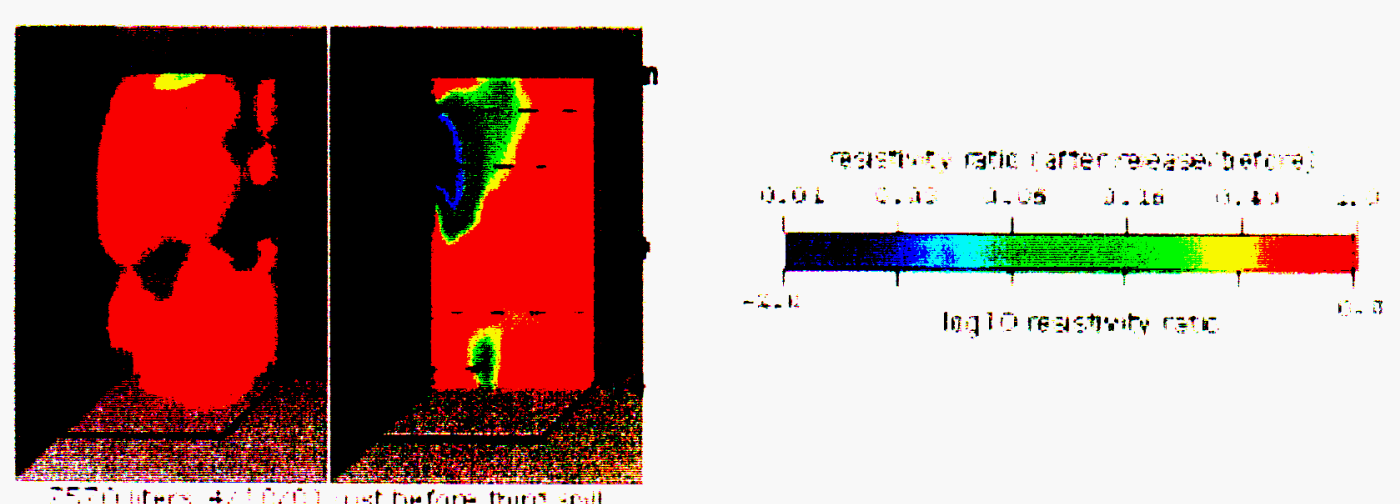

Figure 10. Time history of the pie-shaped region during the course of the first spill. The red labels indicate the approximate beginning and ending times of the spill. The location of the electrode arrays used is depicted by the solid white lines (upper left image). The dashed white lines show the locations of casings for boreholes $\mathrm{H} 2, \mathrm{H} 4$, and H6. The parallelepipeds shown with the black dashed lines indicate the location of fine-grained layers at 6 and $12 \mathrm{~m}$ depth. 


\section{Resistivity changes caused by third sp.}
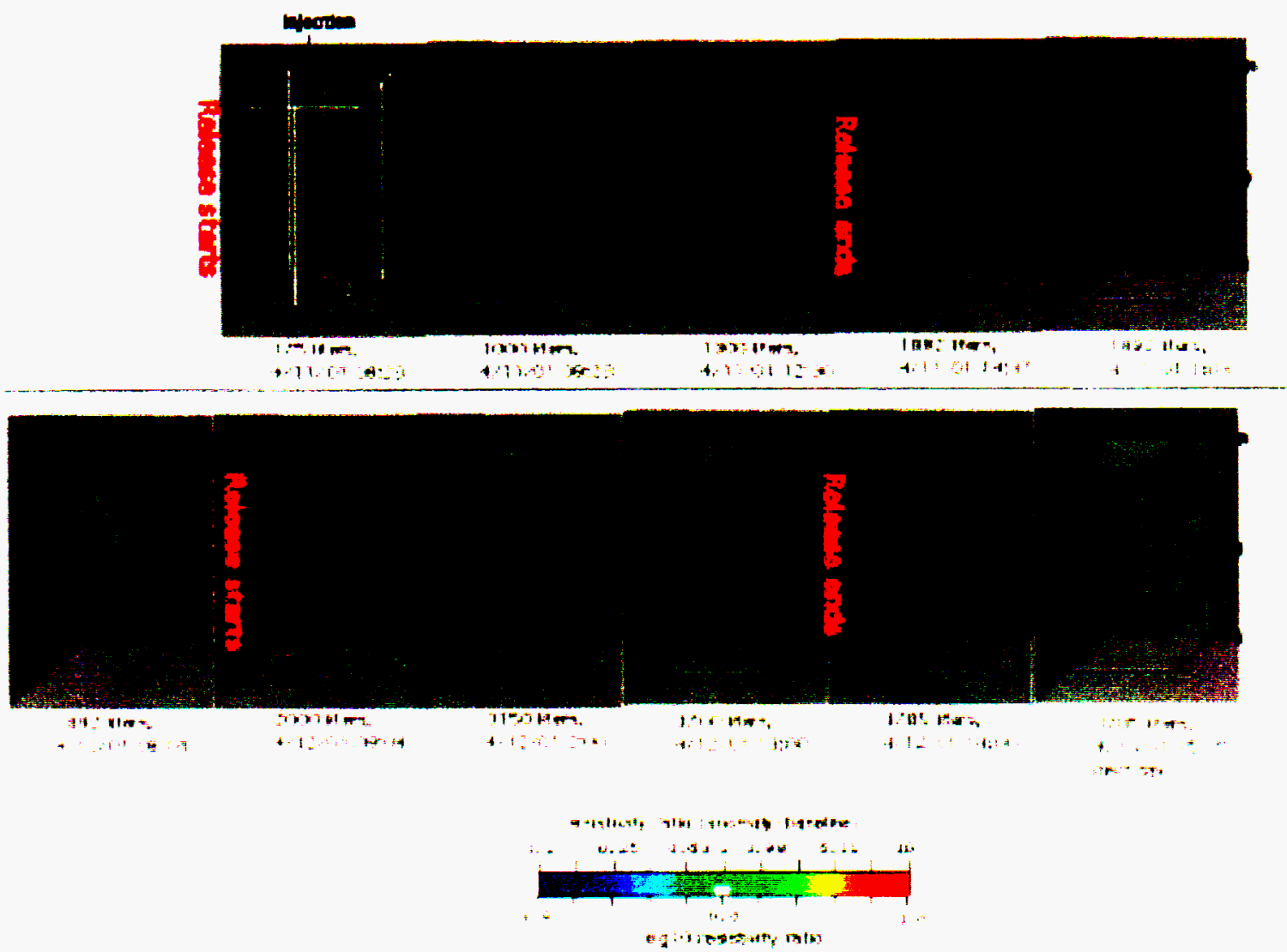

Figure 11. Time history of the pie-shaped region during the course of the third spill. The red labels indicate the approximate beginning and ending times of the two releases associated with the third spill. The location of the electrode arrays used are shown by the solid white lines (upper left image). The dashed white line shows the locations of casings for boreholes $\mathrm{H} 2, \mathrm{H} 4$, and H6. The parallelepipeds shown with the black dashed lines indicate the location of fine-grained layers at 6 and $12 \mathrm{~m}$ depth. 


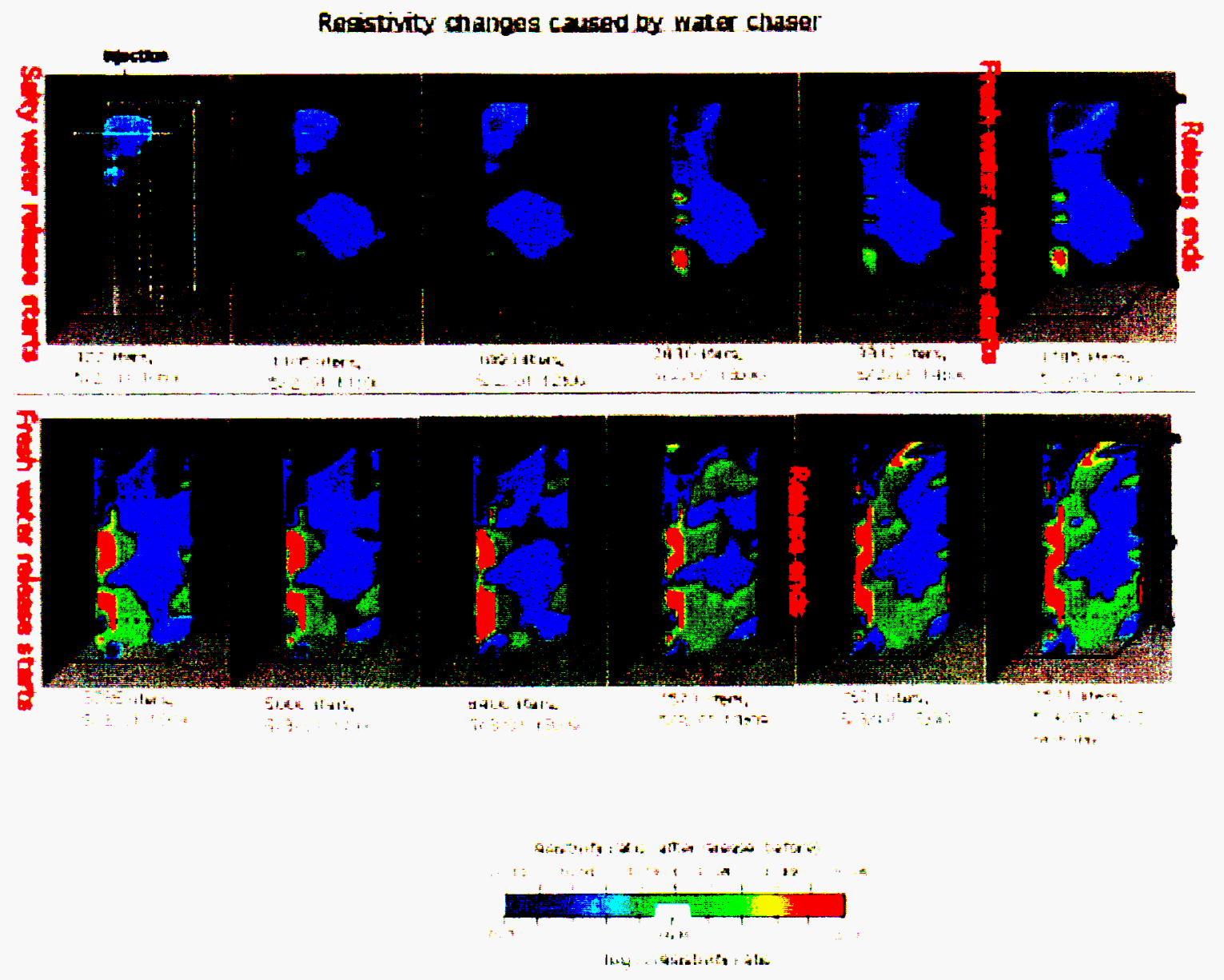

Figure 12. Time history of the pie-shaped region during the course of the sixth spill (fresh water chaser). The approximate beginning and ending times of the two release associated with the chaser spill are indicated by the red labels. The location of the electrode arrays used are shown by the solid white lines (upper left image). The dashed white line shows the locations of casings for boreholes $\mathrm{H} 2, \mathrm{H} 4$, and $\mathrm{H} 6$. The parallelepipeds shown with the black dashed lines indicate the location of fine-grained layers at 6 and $12 \mathrm{~m}$ depth. 


\section{Comparison of resistivity changes cue to low and high ionic strength fluids}

70 unm-m fluid depolacing 30 ahm-m rivid.

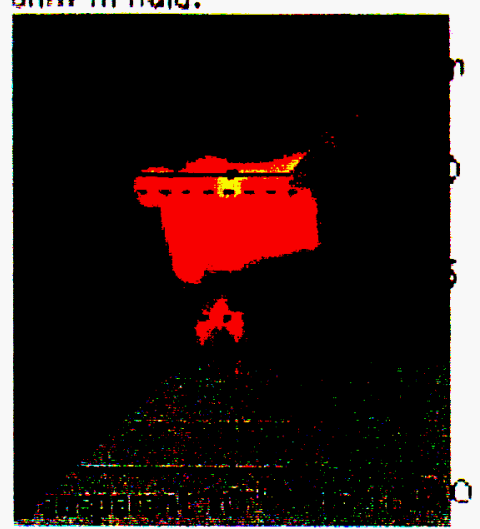

Poco ters mesh

nlwerwatar, bone

inition
0.3 ohm-m nuid displache 30 anm-m fluid.

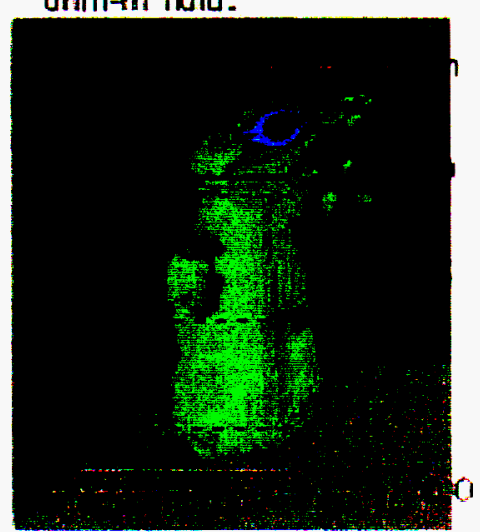

7570 liters highty

concentrated.

Ditne

$4:|1,0|$
4 amm-m tiud tisplacing in nnm-m -iuld.

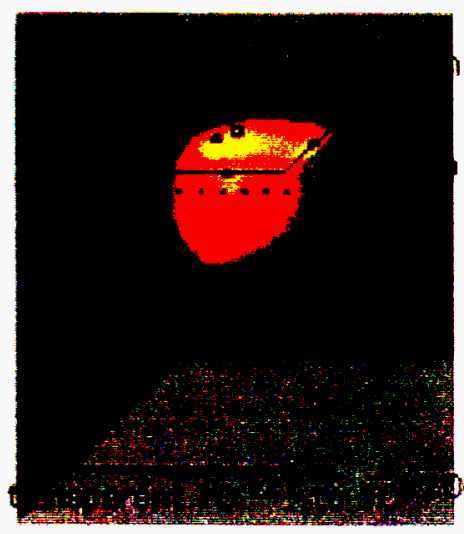

3875 liters of $\times$ Br. S. 10.9
0.3 ohres m riuld dopiacing 0. $\exists$ ohm-m mula.

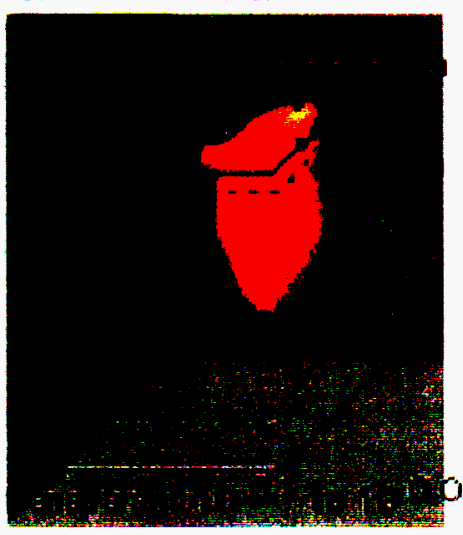

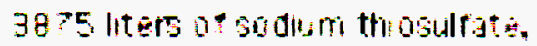

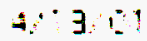

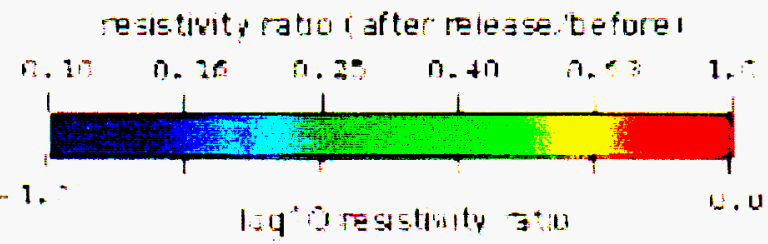

Figure 13. Comparison of tomographs representing the FY00 and FY01 spills. The FY00 spills released low ionic strength fluids and the FY01 spills released high ionic strength fluids. 


\section{Long electrode tomographs: 4/10/01 7570 liters of sodium thio-sulfate}

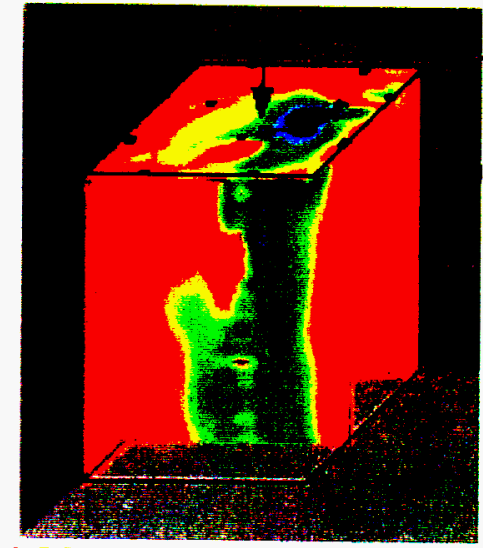

165 point electrode used

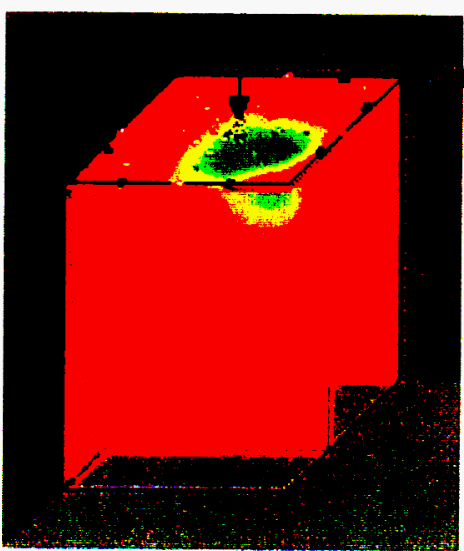

120 point electrodes located on the perime ter of the site combined with with 30 casings (long electrodes)

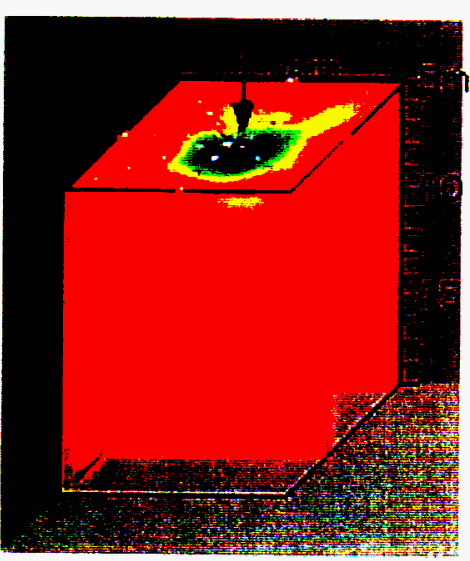

30 steel casings used as long electrodes

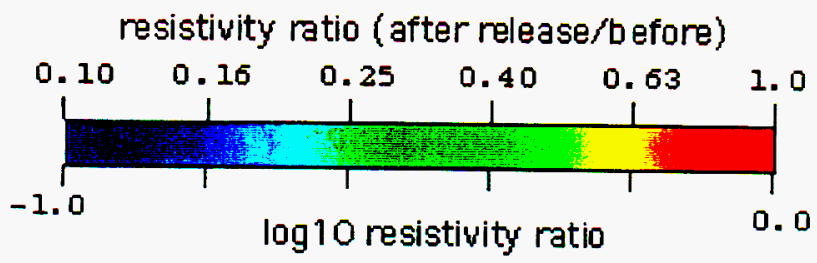

Figure 14. Tomographs calculated with data measured using steel casings as long electrodes. 

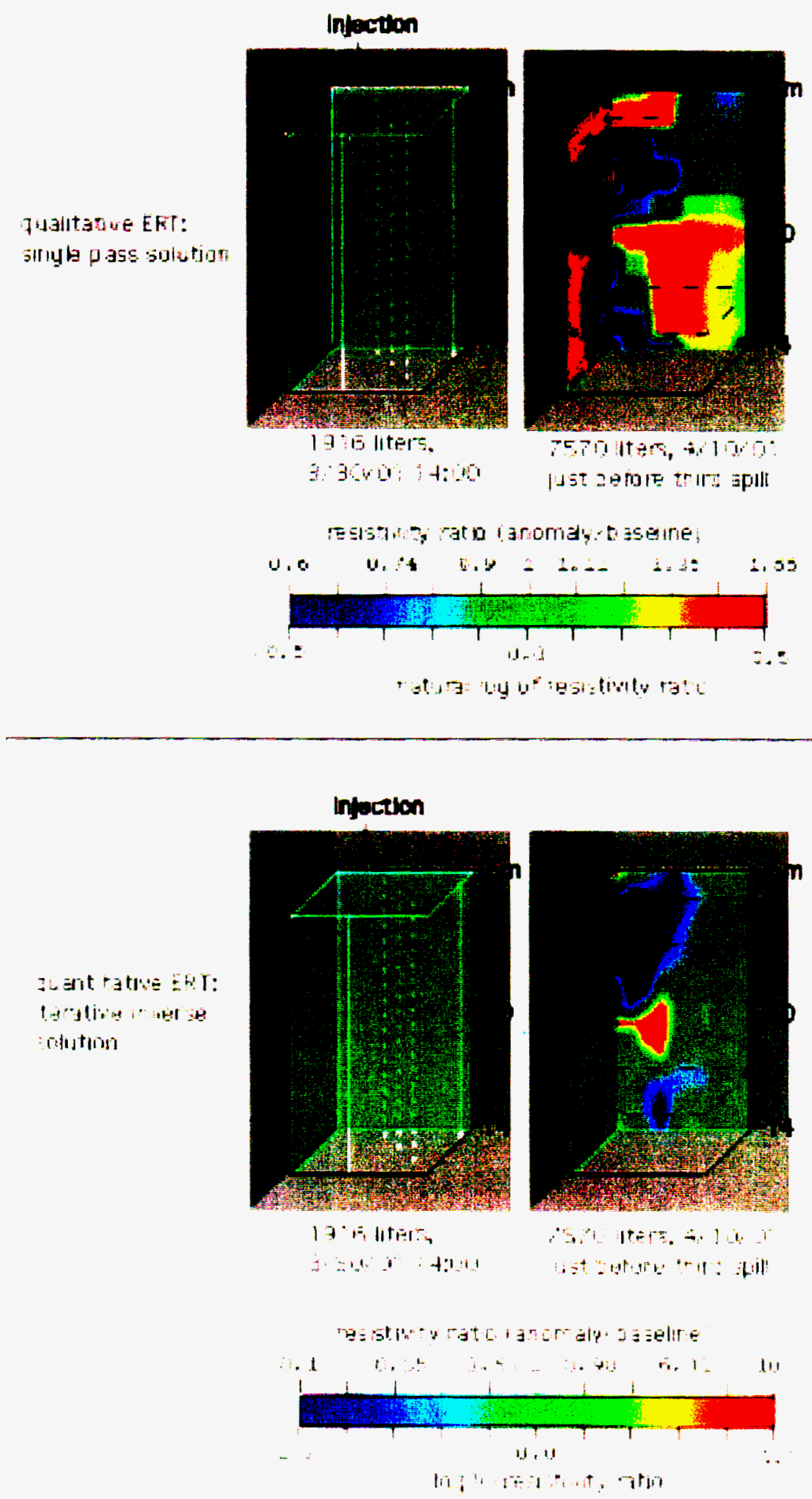

Figure 15. Tomographs of the pie-shaped region calculated using a fast qualitative approach and the quantitative iterative approach (regular ERT). 